University of North Florida

UNIVERSITY of

NORTH FLORIDA.

UNF Digital Commons

\title{
Jahn-Teller Distortions, Cation Ordering and Octahedral Tilting in Perovskites
}

Michael W. Lufaso

University of North Florida, michael.lufaso@unf.edu

Patrick M. Woodward

Follow this and additional works at: https://digitalcommons.unf.edu/achm_facpub

Part of the Chemistry Commons

\section{Recommended Citation}

Lufaso, Michael W. and Woodward, Patrick M., "Jahn-Teller Distortions, Cation Ordering and Octahedral Tilting in Perovskites" (2004). Chemistry Faculty Publications. 3.

https://digitalcommons.unf.edu/achm_facpub/3

This Article is brought to you for free and open access by the Department of Chemistry at UNF Digital Commons. It has been accepted for inclusion in Chemistry Faculty Publications by an authorized administrator of UNF Digital Commons. For more information, please contact Digital Projects.

(C) 2-2004 All Rights Reserved

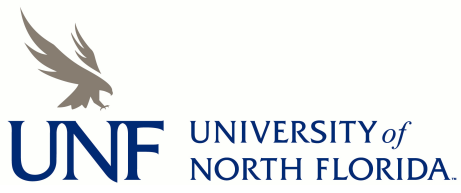


Acta Crystallographica Section B

Structural

Science

ISSN 0108-7681

\section{Michael W. Lufaso and \\ Patrick M. Woodward*}

Ohio State University, Columbus, $\mathrm{OH} 43210$, USA

Correspondence e-mail: woodward@chemistry.ohio-state.edu

\section{Jahn-Teller distortions, cation ordering and octahedral tilting in perovskites}

In transition metal oxides, preferential occupation of specific $d$ orbitals on the transition metal ion can lead to the development of a long-range ordered pattern of occupied orbitals. This phenomenon, referred to as orbital ordering, is usually observed indirectly from the cooperative Jahn-Teller distortions (CJTDs) that result as a consequence of the orbital ordering. This paper examines the interplay between orbital ordering, octahedral tilting and cation ordering in perovskites. Both ternary $A M X_{3}$ perovskites containing an active JahnTeller (J-T) ion on the octahedral site and quaternary $A_{2} M M^{\prime} X_{6}$ perovskites containing a $\mathrm{J}-\mathrm{T}$ ion on one-half of the octahedral sites have been examined. In $A M X_{3}$ perovskites, the tendency is for the occupied $3 d_{3 x^{2}-r^{2}}$ and $3 d_{3 z^{2}-r^{2}}$ orbitals to order in the $a c$ plane, as exemplified by the crystal structures of $\mathrm{LaMnO}_{3}$ and $\mathrm{KCuF}_{3}$. This arrangement maintains a favorable coordination environment for the anion sites. In $A M X_{3}$ perovskites, octahedral tilting tends to enhance the magnitude of the J-T distortions. In $A_{2} M M^{\prime} X_{6}$ perovskites, the tendency is for the occupied $3 d_{3 z^{2}-r^{2}}$ orbitals to align parallel to the $c$ axis. This pattern maintains a favorable coordination environment about the symmetric $M^{\prime}$-cation site. The orbital ordering found in rock-salt ordered $A_{2} M M^{\prime} X_{6}$ perovskites is compatible with octahedral rotations about the $c$ axis (Glazer tilt system $a^{0} a^{0} c^{-}$) but appears to be incompatible with $\mathrm{GdFeO}_{3}$-type octahedral tilting (tilt system $\left.{ }^{-} b^{+} a^{-}\right)$.

\section{Introduction}

Perovskites containing Jahn-Teller ions (i.e. $\mathrm{Cu}^{2+}$ and $\mathrm{Mn}^{3+}$ ) on the octahedral site exhibit interesting physical properties, including charge ordering, spin ordering and cooperative Jahn-Teller distortions. In octahedral coordination, the firstrow transition-metal cations $\mathrm{Mn}^{3+}$ (high-spin) and $\mathrm{Cu}^{2+}$ have electron configurations $\left(t_{2 g}\right)^{3}\left(e_{g}\right)^{1}$ and $\left(t_{2 g}\right)^{6}\left(e_{g}\right)^{3}$, respectively. The Jahn-Teller $(\mathrm{J}-\mathrm{T})$ theorem predicts that a distortion of the ideal octahedral geometry will occur, thus providing an energetic stabilization by removing the electronic degeneracy of the highest occupied molecular orbital (Kanamori, 1960). It has been shown that a larger energetic stabilization is realized when the primary distortion mechanism is elongation of two bonds trans to each other and contraction of the remaining bonds, as opposed to the inverse distortion, i.e. contraction of two trans bonds and elongation of the remaining four (Burdett, 1981). In extended solids, ionic effects and lattice strains can stabilize less symmetric distortions. For example, a distortion where two $M-X$ bonds shorten and two $M-X$ bonds lengthen, denoted as $Q 2$, is typically observed in ternary perovskites such as $\mathrm{LaMnO}_{3}$. Changing the symmetry and/or the identity and arrangement of the surrounding
Received 28 August 2003 Accepted 20 November 2003 
'symmetric' ions often leads to a change in the distortion at the J-T ion. A distortion where four bonds contract and two bonds expand, denoted as $Q 3$, is typically observed in ordered perovskites such as $\mathrm{Sr}_{2} \mathrm{CuWO}_{6}$ (Gateshki \& Igartua, 2003). Coupling of cooperative $\mathrm{J}-\mathrm{T}$ distortions and octahedral-tilting distortions (Glazer, 1972; Woodward, 1997a,b) is another factor that can play a role, although the interaction between these two common distortions is not well understood.

Experimentally, the charge and spin configurations have been investigated by neutron and electron-diffraction techniques. Direct observance of the orbital ordering is not easily accomplished. Quantitative convergent-beam electrondiffraction techniques have been used to identify the occupied $3 d_{3 x^{2}-r^{2}}$ and $3 d_{3 z^{2}-r^{2}}$ orbitals in $\mathrm{LaMnO}_{3}$ (Jiang et al., 2002). (In the notation more familiar to chemists, these orbitals are $3 d_{z^{2}}$-type orbitals, oriented in the $x$ and $z$ directions, respectively.) Resonant X-ray scattering uses incident photons tuned near the $K$-absorption edge of the element undergoing orbital ordering, in order to observe orbital ordering directly (Murakami, Kawada et al., 1998; Paolasini et al., 2002). Dipole resonant X-ray scattering studies confirmed the presence of orbital ordering of $\mathrm{Mn} 3 d$ orbitals in $\mathrm{LaMnO}_{3}$ (Murakami, Hill et al., 1998) and simultaneous charge and orbital ordering in $\mathrm{Pr}_{0.5} \mathrm{Ca}_{0.5} \mathrm{MnO}_{3}$ (Zimmermann et al., 2001). The orientation of the long $M-X$ bonds in the crystal is in agreement with orbital-ordering results obtained from X-ray resonant scattering experiments, confirming the long-held belief that the orbital-ordering pattern can be inferred indirectly, yet accurately, from the crystal structure. A quantitative measure of the magnitude of the $\mathrm{J}-\mathrm{T}$ distortion is given by the octahedral distortion parameter $(\Delta d)$ defined in (1), where $d$ is the mean $M-X$ bond distance and $d_{n}$ are the individual $M-X$ bond distances (Alonso et al., 2000):

$$
\Delta d=(1 / 6) \sum_{n=1,6}\left[\left(d_{n}-d\right) / d\right]^{2} \text {. }
$$

This paper examines the influence of octahedral tilting and cation ordering on orbital ordering in perovskites containing J-T cations. Systematic comparisons are made with crystal structures with a symmetric octahedral ion of approximately the same size, in order to separate the effects of octahedral tilting and the cooperative Jahn-Teller distortion (CJTD). The combined effects of cation ordering, octahedral tilting and J-T ions on the structural features of perovskites are described below.

\section{Distortion mechanisms in perovskites}

The tolerance factor was first proposed by Goldschmidt (1926), in order to quantify the size match of the $A$ and $B$ cations to the cubic perovskite topology. The tolerance factor, $\tau$, is defined as

$$
\tau=d(A-X) /\left[2^{1 / 2} d(B-X)\right],
$$

where $d(A-X)$ is the ideal $A-X$ distance and $d(B-X)$ is the weighted average of the ideal $M-X$ and $M^{\prime}-X$ distances. Throughout this manuscript, tolerance factors are calculated with the SPUDS software package (Lufaso \& Woodward, 2001). SPuDS uses the bond-valence model to calculate the ideal $A-X, M-X$ and $M^{\prime}-X$ distances, assuming 12 equidistant $A-X$ bonds and six equidistant $M-X$ and $M^{\prime}-X$ bonds. Perovskites with a tolerance factor equal to or greater than unity often exhibit no octahedral tilting. More commonly, the $A$ cation is too small for the corner-sharing octahedral network, and an octahedral-tilting distortion takes place (Woodward, 1997b). Cooperative tilting of the undistorted octahedra occurs to shorten the $A-X$ bonds and thereby improve the coordination environment and bonding of the $A$-site cation. The various combinations of octahedral tilting and the resulting space-group symmetries have been described previously (Glazer, 1972, 1975; Woodward, 1997a; Howard \& Stokes, 1998). In fact, at room temperature, the aristotype cubic perovskite structure is realized in only a small percentage of perovskites. The most commonly observed octahedral tilt system, reported for more than half of the ternary perovskites at room temperature, lowers the symmetry from Pm3m to Pnma (Lufaso \& Woodward, 2001). This type of tilting, described as $a^{-} b^{+} a^{-}$in Glazer's (1972) notation, is normally associated with $\mathrm{GdFeO}_{3}$ and/or the mineral perovskite, $\mathrm{CaTiO}_{3}$. Octahedral-site cation ordering also modifies the space-group symmetry. The space-group symmetries that result from the combination of rock-salt ordering and octahedral tilting have been reported on several occasions (Aleksandrov \& Misjul, 1981; Woodward, 1997a; Gateshki et al., 2003; Howard et al., 2003). Large differences in size (greater than $0.1 \AA$ ) and/or oxidation state (greater than two) are two factors that favor cation ordering on the octahedral site (Anderson et al., 1993).

Cooperative Jahn-Teller distortions describe the orbitalordering arrangement and occur to minimize the elastic energy (Goodenough, 1998). The CJTD in $\mathrm{KCuF}_{3}$ is complex because of the numerous ways in which the crystals may form stacking errors. The type and concentration of these stacking faults can influence the space-group determination, thus making assignment of a space group difficult. Consequently, the structure of $\mathrm{KCuF}_{3}$ has been reported with space-group symmetries I4/mcm (Hutchings et al., 1969; Buttner et al., 1990), P4/mbm (Hutchings et al., 1969) and $P 2{ }_{1} 2_{1} 2_{1}$ (Hidaka et al., 1998). Crystallization of $\mathrm{KCuF}_{3}$ in space group $I 4 / \mathrm{mcm}$, with three distinct $\mathrm{Cu}-\mathrm{F}$ bond lengths and a CJTD with long and short $\mathrm{Cu}-\mathrm{F}$ bonds alternating in the $a b$ plane, was reported by Buttner et al. (1990). Viewed perpendicular to the $a b$ plane, there are two possible orientations of the $\mathrm{CuF}_{2}$ layers. The structure is said to be $d$-type $(P 4 / \mathrm{mbm})$ when the pattern of long and short $\mathrm{Cu}-\mathrm{F}$ bonds is the same from one layer to the next (layers separated by a mirror plane), whereas when the orientations of the long and short $\mathrm{Cu}-\mathrm{F}$ bonds are rotated by $90^{\circ}$ from one layer to the next, the structure is designated as $a$-type $(I 4 / \mathrm{mcm})$ (Hutchings et al., 1969). The $\mathrm{KCuF}_{3}$ structure exists in both forms (even in the same crystal), with the $a$-type favored. The $a$-type arrangement is illustrated in Fig. 1.

In $A_{2} M M^{\prime} X_{6}$ perovskites, the octahedral cations can order in one of three ways, viz. (a) in a three-dimensional rock-salt 
pattern, (b) in layers or (c) in chains (Anderson et al., 1993). Of these three, rock-salt ordering is far and away the most common. Quaternary perovskites containing a $\mathrm{J}-\mathrm{T}$ ion manifest CJTDs that vary with changes in the cation ordering. Crystal structures of $A_{2} \mathrm{Cu}_{M} \mathrm{O}_{6}(A=\mathrm{Sr}$ and $\mathrm{Ba}$, and $M=\mathrm{W}$ and $\mathrm{Te}$ ) were found to have $I 4 / \mathrm{m}$ space-group symmetry, with rock-salt ordering of $\mathrm{Cu}^{2+}$ and $M^{6+}(M=\mathrm{Te}$ and $\mathrm{W})$ and $a^{0} a^{0} c^{-}$rotations of the octahedra (Iwanaga et al., 1999; Gateshki \& Igartua, 2003). In these compounds, all of the long $\mathrm{Cu}-\mathrm{O}$ bonds orient parallel to the $c$ axis. $\mathrm{La}_{2} \mathrm{CuSnO}_{6}$ possesses an unusual layered arrangement of $\mathrm{Sn}^{4+}$ and $\mathrm{Cu}^{2+}$ ions, with a large $\mathrm{J}-\mathrm{T}$ distortion about the latter ion (Anderson \& Poeppelmeier, 1991), but retains a CJTD in which the long $\mathrm{Cu}-\mathrm{O}$ bonds align in a direction that is nearly parallel to the $c$ axis (the long $\mathrm{Cu}-\mathrm{O}$ bonds are not strictly parallel to the $c$ axis because of octahedral tilting). Charge ordering occurs near $160 \mathrm{~K}$ for $\mathrm{NdSrMn}_{2} \mathrm{O}_{6}$, resulting in a structure with chains of $\mathrm{Mn}^{3+} \mathrm{O}_{6}$ and $\mathrm{Mn}^{4+} \mathrm{O}_{6}$ (Woodward et al., 1999). Another compound that has been reported with this type of

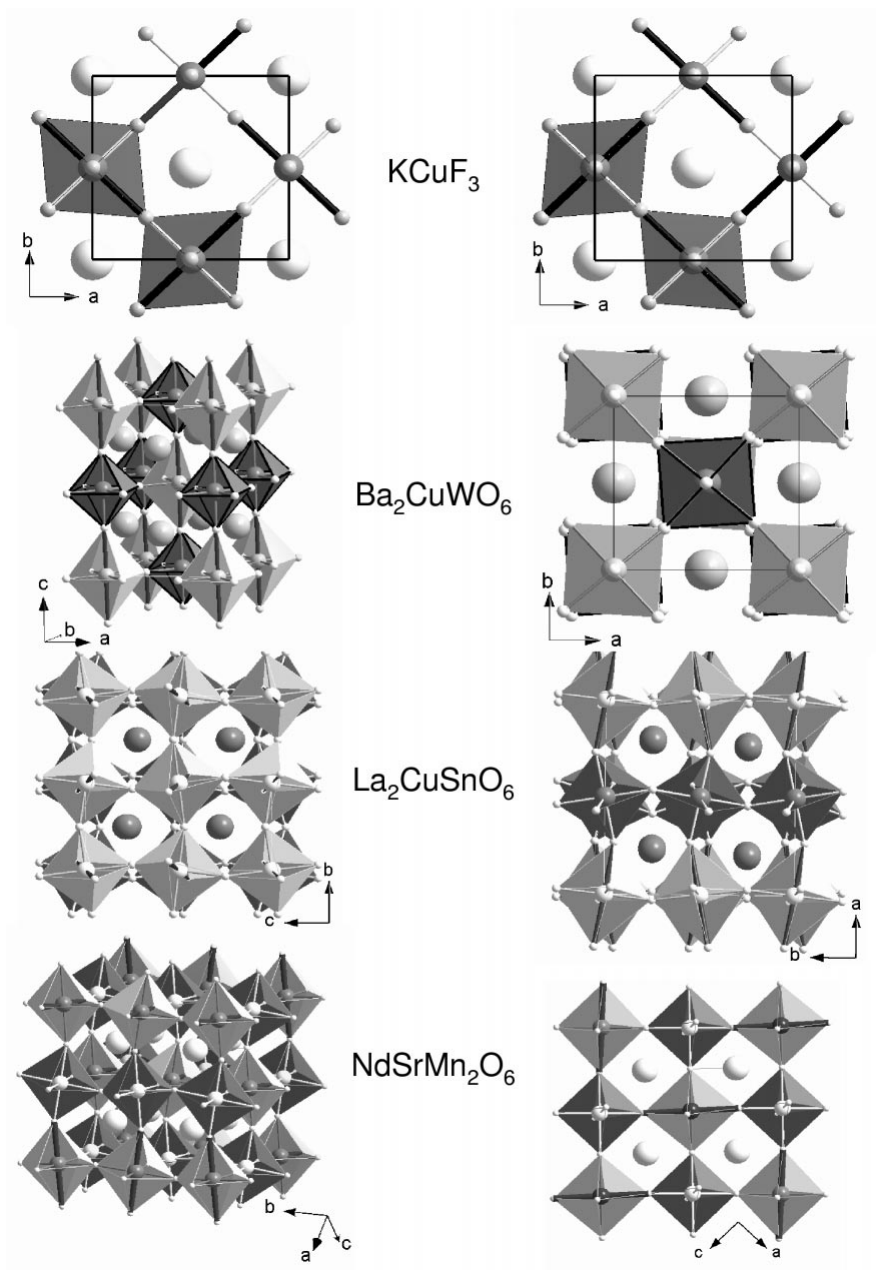

Figure 1

Crystal structures showing CJTDs in combination with various types of cation ordering. Lightly shaded polyhedra represent J-T-distorted octahedra, while darkly shaded polyhedra represent symmetric octahedra. Long $M-X$ bonds are depicted as thick black lines, whereas thinner lines are used for the short and medium-length $M-X$ bonds. For $\mathrm{KCuF}_{3}$, the two figures represent successive layers of the structure. charge and orbital ordering is $\mathrm{LaCaMn}_{2} \mathrm{O}_{6}$ (Radaelli et al., 1997). In compounds with this type of charge ordering, the long $\mathrm{Mn}^{3+}-\mathrm{O}$ bonds lie in the $a c$ plane, in a fairly complex arrangement that is compatible with the charge and magnetic ordering. The most common CJTDs for each type of cation ordering discussed above are shown in Fig. 1. Recent results suggest the possibility that electron localization in compounds belonging to the $A \mathrm{LnMn}_{2} \mathrm{O}_{6}$ family may actually involve dimerization of two Mn atoms into a Zener polaron, rather than ordering of distinct $\mathrm{Mn}^{3+}$ and $\mathrm{Mn}^{4+}$ ions (Daoud-Aladine et al., 2002). Regardless of how this controversy is settled, there is no a priori reason why the topology of the chainordered structure could not be realized when the charge difference between different cation sites is small.

The bond-valence concept (Brown, 1978, 2003; Brese \& O'Keeffe, 1991) has been used to understand and predict the structures of oxides in general and perovskites in particular (Lufaso \& Woodward, 2001). The valence of each bond is calculated on the basis of the ions involved and the bond distance. By summing the individual bond valences, a bondvalence sum (BVS) is obtained for each ion. Normally, this sum should be near the oxidation state of the ion. The need to maintain a reasonable bond-valence sum at the anion sites plays an important role in determining the most favorable orbital-ordering arrangement. A large J-T distortion at the octahedral-site cation causes a loss of bonding to the anion involved in the resulting long $M-X$ bond. However, this anion typically forms a short bond to the octahedral-site cation on its opposite side, in order to maintain a reasonable bond-valence sum. For example, consider the crystal structure of $\mathrm{KCuF}_{3}$ (Buttner et al., 1990). Two crystallographically and chemically distinct $\mathrm{F}$-atom sites are present. The fluoride ion that resides on the $8 h$ site has one short and one long $\mathrm{Cu}-\mathrm{F}$ bond, while the fluoride ion that sits on the $4 b$ site forms two intermediate-length bonds to the $\mathrm{Cu}$ atom. Each environment provides a satisfactory bonding arrangement for fluorine, as shown by the bond-valence sums. Bond-valence calculations show that the short $\mathrm{Cu}-\mathrm{F}(8 h)$ bond $[1.8888(4) \AA]$ contributes 0.45 v.u. (valence units), the long $\mathrm{Cu}-\mathrm{F}(8 h)$ bond [2.2527 (4) $\AA$ ] contributes 0.17 v.u. and four $\mathrm{K}-\mathrm{F}$ bonds [2.8585 (3) $\AA$ ] contribute a total of 0.38 v.u., for a BVS of 1.00 v.u. at the $F(8 h)$ site. A similar analysis of the $F$ atom on the $4 b$ site reveals two medium-length $\mathrm{Cu}-\mathrm{F}(4 b)$ bonds [1.9622 (2) $\AA$ ], each of which contributes 0.37 v.u., and four $\mathrm{K}-\mathrm{F}$ bonds $[2.9285$ (3) $\AA]$ that contribute a total of 0.32 v.u., for a BVS of 1.06 v.u. at the $\mathrm{F}(4 b)$ site. This arrangement is much more favorable than a CJTD where all of the long $\mathrm{Cu}-$ $\mathrm{F}$ bonds are oriented parallel to each other. In that case, one F-atom site would have two long bonds to the $\mathrm{Cu}$ atom, while another anion site would have two short bonds to the $\mathrm{Cu}$ atom and the third site would have two intermediate-length $\mathrm{Cu}-\mathrm{F}$ bonds. Clearly, the first two F-atom sites would have BVSs that deviate significantly from 1.00 v.u., barring radical changes in the $\mathrm{K}-\mathrm{F}$ bond distances.

The anion environment changes in the ordered $A_{2} M M^{\prime} \mathrm{O}_{6}$ perovskite structure, and this change impacts the orbital ordering. In general, the $M^{\prime}$ cation is not a J-T ion and will 
Table 1

Bond-valence sums (v.u.) of ions in experimental crystal structures of $\mathrm{KCuF}_{3}, \mathrm{Ba}_{2} \mathrm{CuWO}_{6}, \mathrm{La}_{2} \mathrm{CuSnO}_{6}$ and $\mathrm{NdSrMn}_{2} \mathrm{O}_{6}$.

\begin{tabular}{lllll}
\hline & $\mathrm{KCuF}_{3}$ & $\mathrm{Ba}_{2} \mathrm{CuWO}_{6}$ & $\mathrm{La}_{2} \mathrm{CuSnO}_{6}$ & \multicolumn{1}{c}{$\mathrm{NdSrMn}_{2} \mathrm{O}_{6}$} \\
\hline \multirow{2}{*}{ s site } & 1.09 & 2.48 & $2.90,3.00,2.75$, & $\begin{array}{l}2.59,2.57,2.63, \\
\end{array}$ \\
& & & 2.93 & 2.62 \\
Oct. site (J-T) & 1.98 & 1.90 & $2.05,2.03$ & $3.49,3.49$ \\
Oct. site (Sym.) & - & 5.92 & $3.98,3.98$ & 4.05 \\
$X$ (long $M-X)$ & 1.00 & 2.19 & $1.96,1.91$ & $2.14,2.14$ \\
$X$ & 1.06 & 2.10 & $1.93,1.95,1.96$, & $2.04,2.05,2.20$, \\
& & & $1.92,2.04,2.18$ & $2.22,2.18,2.18$ \\
\hline
\end{tabular}

prefer a fairly symmetric coordination environment. This conformation disrupts the simultaneous formation of both long and short bonds at a given anion site, thereby reducing the stabilization of the $a b$-plane ordering seen in $\mathrm{KCuF}_{3}$. As an illustration, consider the crystal structure (space group $I 4 / m$ ) of $\mathrm{Ba}_{2} \mathrm{CuWO}_{6}$ (Iwanaga et al., 1999). In $\mathrm{Ba}_{2} \mathrm{CuWO}$, and in $A_{2}{\mathrm{Cu} M \mathrm{O}_{6}}_{6}$ compositions in general ( $A=\mathrm{Ba}$ and $\mathrm{Sr}$, and $M=\mathrm{W}$ and $\mathrm{Te}$ ), all of the long $\mathrm{Cu}-\mathrm{O}$ bonds are directed parallel to the $c$ axis. A bond-valence analysis of the $\mathrm{Ba}_{2} \mathrm{CuWO}_{6}$ structure shows that the $\mathrm{O}$ atom that resides on the $4 c$ site forms a long bond [2.41 (2) $\AA, 0.14$ v.u.] to the $\mathrm{Cu}$ atom, a relatively short bond to the W atom [1.90 (2) $\AA$, 1.05 v.u.] and four bonds to $\mathrm{Ba}$ atoms [2.79 (2) $\mathrm{A}$, $4 \times 0.25$ v.u.]. The $\mathrm{O}$ atom on the $8 d$ site forms a much shorter bond to the $\mathrm{Cu}$ atom [2.01 (2) $\AA$, 0.41 v.u.], but the structure compensates for this bond by forming a slightly longer bond to the W atom [1.93 (2) $\AA$, 0.96 v.u.] and noticeably longer bonds to the Ba atoms $[2 \times 2.83$ (3) $\AA, 2 \times 0.23$ v.u.; $2 \times 3.01$ (3) $\AA$, $2 \times 0.14$ v.u.]. The anion BVSs are 2.19 v.u. for the $\mathrm{O}$ atom on the $4 c$ site and 2.11 v.u. for the $\mathrm{O}$ atom on the $8 d$ site. In $\mathrm{La}_{2} \mathrm{CuSnO}_{6}$, the $\mathrm{O}$ atom involved in the long $\mathrm{Cu}-\mathrm{O}$ bonds compensates by forming shorter $\mathrm{Sn}-\mathrm{O}$ bonds. The chargeordered structure of $\mathrm{NdSrMn}_{2} \mathrm{O}_{6}$ has three distinct $\mathrm{Mn}$ sites and a more complicated orbital-ordering scheme, but once again consideration of the bonding at the $\mathrm{O}$ atoms is a very useful way to understand the structure. Bond-valence sums for each of the ions in the four structures are listed in Table 1.

It is interesting to consider how the presence of octahedral tilting influences the orbital ordering in both ternary $A M X_{3}$ and ordered quaternary $A_{2} M M^{\prime} X_{6}$ perovskites, and this question is the focus of the next two sections of this paper. The $M-X$ bond lengths, octahedral distortion parameters, spacegroup symmetries and octahedral tilt systems for a representative cross-section of perovskites exhibiting a CJTD, namely $\mathrm{LaMnO}_{3}$ (Rodriguez-Carvajal et al., 1998), $\mathrm{KCuF}_{3}$ (Buttner et al., 1990), $\mathrm{Sr}_{2} \mathrm{CuWO}_{6}$ (Iwanaga et al., 1999), and $\mathrm{La}_{2} \mathrm{CuTiO}_{6}$ (Palacin et al., 1993), are shown in Table 2.

\section{Octahedral tilting and CJTDs in $A M X_{3}$ systems}

Compounds with the composition $A \mathrm{CuF}_{3}(A=\mathrm{Na}, \mathrm{K}$ and $\mathrm{Rb})$ prefer to adopt an $a$-type CJTD (space group $I 4 / \mathrm{mcm}$ ). No octahedral tilting occurs for $A \mathrm{CuF}_{3}(A=\mathrm{K}$ and $\mathrm{Rb})$ and the structure retains $\mathrm{F}-\mathrm{Cu}-\mathrm{F}$ bond angles of $90^{\circ}(A=\mathrm{K}$ : Buttner et al., 1990; $A=\mathrm{Rb}$ : Kaiser et al., 1990), whereas
Table 2

$M-X$ bond lengths, $\Delta d$, symmetries and tilting axes for a representative cross-section of perovskites containing a formal $\mathrm{J}-\mathrm{T}$ ion $\left(\mathrm{La}_{2} \mathrm{CuTiO}_{6}\right.$, $\mathrm{LaMnO}_{3}, \mathrm{KCuF}_{3}$ and $\mathrm{Sr}_{2} \mathrm{CuWO}_{6}$ ).

\begin{tabular}{lllll}
\hline & $\mathrm{La}_{2} \mathrm{CuTiO}_{6}$ & $\mathrm{LaMnO}_{3}$ & $\mathrm{KCuF}_{3}$ & $\mathrm{Sr}_{2} \mathrm{CuWO}_{6}$ \\
\hline$M-X(\mathrm{l})(\AA) \times 2$ & $2.033(4)$ & $2.178(1)$ & $2.2527(4)$ & $2.32(3)$ \\
$M-X(\mathrm{~m})(\AA) \times 2$ & $2.022(4)$ & $1.9680(3)$ & $1.9622(2)$ & $1.95(3)$ \\
$M-X(\mathrm{~s})(\AA) \times 2$ & $2.0072(14)$ & $1.907(1)$ & $1.8888(4)$ & $1.95(3)$ \\
$\Delta d\left(\times 10^{-4}\right)$ & 0.27 & 33.1 & 59.7 & 70.8 \\
Symmetry & $P n m a$ & $P n m a$ & $I 4 / m c m$ & $I 4 / m$ \\
Tilt system & $a^{-} b^{+} a^{-}$ & $a^{-} b^{+} a^{-}$ & $a^{0} a^{0} c^{-}$ & $a^{0} a^{0} c^{-}$ \\
\hline
\end{tabular}

$\mathrm{NaCuF}_{3} \quad(\tau=0.918)$ exhibits significant octahedral tilting. $\mathrm{NaCuF}_{3}$ has four similar coordination environments for the $\mathrm{Cu}$ atom, with strongly distorted average $\mathrm{F}-\mathrm{Cu}-\mathrm{F}$ angles $(91$, 94 and $105^{\circ}$; Kaiser et al., 1990). Three distinct $\mathrm{Cu}-\mathrm{F}$ bond distances (average $\mathrm{Cu}-\mathrm{F}$ bond distances presented for $\left.\mathrm{NaCuF}_{3}\right)$ are shown for $A \mathrm{CuF}_{3}(A=\mathrm{Na}, \mathrm{K}$ and $\mathrm{Rb})$ in Fig. 2. The three distinct $\mathrm{Cu}-\mathrm{F}$ bond distances are similar for $A=\mathrm{Na}$ and $\mathrm{K}$; however, the larger size of the $\mathrm{Rb}$ atom ( $\tau=1.089$ ) causes a stretching of the octahedron, with the longest (weakest) bond undergoing the largest expansion.

The rare-earth manganates $R \mathrm{MnO}_{3}(R=\mathrm{La}, \mathrm{Pr}, \mathrm{Nd}, \mathrm{Dy}, \mathrm{Tb}$ and Ho) have been studied extensively. They crystallize in tilt system $a^{-} b^{+} a^{-}$with Pnma symmetry, and accurate structures have been obtained from neutron powder diffraction studies (Rodriguez-Carvajal et al., 1998; Alonso et al., 2000). The CJTD in these compounds, indicative of orbital ordering, is the $d$-type arrangement seen sometimes in $\mathrm{KCuF}_{3}$, with an $a^{-} b^{+} a^{-}$octahedral-tilting distortion superimposed. The ordered arrangement of the long bonds is shown looking down the $b$ axis of $\mathrm{LaMnO}_{3}$ in Fig. 3 .

To separate the effects of the $\mathrm{J}-\mathrm{T}$ distortion and the octahedral-tilting distortion it is insightful to compare $R \mathrm{MnO}_{3}$

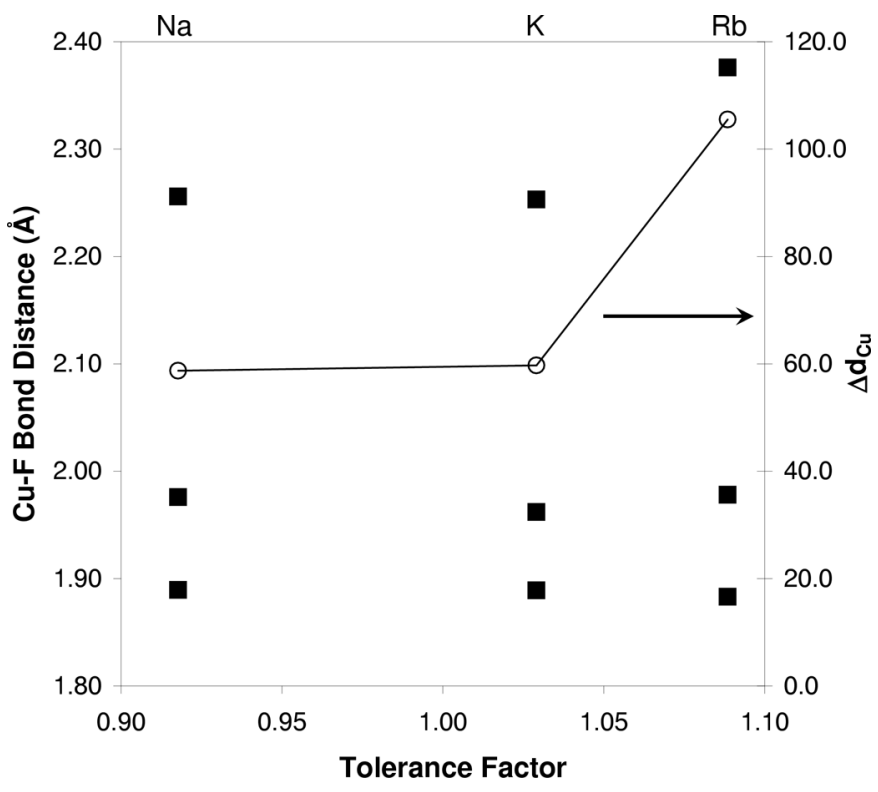

Figure 2

$\mathrm{Cu}-\mathrm{F}$ distances versus tolerance factor for the $\mathrm{ACuF}_{3}$ series (squares). $\Delta d_{\mathrm{Cu}}$ is represented by open circles. The symbols are in order of increasing tolerance factor $(A=\mathrm{Na}, \mathrm{K}$ and $\mathrm{Rb})$. 
perovskites with $R \mathrm{FeO}_{3}$ perovskites. The $\mathrm{Fe}^{3+}$ and $\mathrm{Mn}^{3+}$ ions have identical crystal radii ( $0.785 \AA$; Shannon, 1976). Consequently, for the same rare-earth cation, $R \mathrm{FeO}_{3}$ and $R \mathrm{MnO}_{3}$ perovskites will have the same tolerance factor. Thus the approximate crystal structure in the absence of a J-T distortion can be obtained by replacing $\mathrm{Mn}^{3+}$ with the octahedrally symmetric $\mathrm{Fe}^{3+}$ ion. Examination of the $R \mathrm{FeO}_{3}(R=\mathrm{La}, \mathrm{Pr}$, $\mathrm{Nd}, \mathrm{Sm}, \mathrm{Eu}, \mathrm{Gd}, \mathrm{Tb}, \mathrm{Er}$, Dy, Ho, Y, Tm, Yb and Lu; Marezio et al., 1970) and $R \mathrm{MnO}_{3}(R=\mathrm{La}, \mathrm{Pr}, \mathrm{Nd}, \mathrm{Dy}, \mathrm{Tb}$ and $\mathrm{Ho})$ series confirms that both sets of compounds crystallize with the same tilt system and space group. A plot of the $\mathrm{Mn}-\mathrm{O}$ bond distances versus the tolerance factor is shown in Fig. 4, while the $\mathrm{O}-\mathrm{Mn}-\mathrm{O}$ bond angles versus the tolerance factor are shown in Fig. 5. The distortion of the $\mathrm{Mn}-\mathrm{O}$ bond distances and the $\mathrm{O}-\mathrm{Mn}-\mathrm{O}$ bond angles increases as the tolerance factor decreases (larger octahedral-tilt angle). The tendency for the individual $\mathrm{O}-\mathrm{Mn}-\mathrm{O}$ angles to deviate from $90^{\circ}$ increases as the length of the long $\mathrm{Mn}-\mathrm{O}$ bonds increase. This behavior is quite reasonable, as these bonds are weaker and more susceptible to distortion, not to mention the fact that the $\mathrm{O}-\mathrm{O}$ repulsions are lessened by elongation of the $\mathrm{Mn}-\mathrm{O}$ bonds. The bond-angle distortion parameter is defined as

$$
\Delta \theta_{X M X}=(1 / 3)\left\{\sum_{n=1,3}\left[\theta_{X M X}(n)-\left\langle\theta_{X M X}\right\rangle\right] /\left\langle\theta_{X M X}\right\rangle\right\}^{2},
$$

where $\theta_{X M X}$ represents the individual cis $\mathrm{O}-\mathrm{Mn}-\mathrm{O}$ bond angles and $\left\langle\theta_{X M X}\right\rangle$ is the mean of all cis $\mathrm{O}-\mathrm{Mn}-\mathrm{O}$ bond angles greater than $90^{\circ}$ (an equivalent set of bond angles equally displaced in the opposite direction from $90^{\circ}$ is also present). Fig. 5 shows that the bond-angle distortion is enhanced in the $R \mathrm{MnO}_{3}$ series for the smaller rare-earth ions (Dy, $\mathrm{Tb}$ and $\mathrm{Ho}$ ), whereas the distortions are similar to those in the $R \mathrm{FeO}_{3}$ series for the larger rare-earth ions.

A comparison of lattice parameters for $A \mathrm{MnO}_{3}$ and $A \mathrm{FeO}$ is shown in Fig. 6. Since both $A \mathrm{MnO}_{3}$ and $A \mathrm{FeO}_{3}$ have approximately the same degree of tilting (for the same $A$-site cation), a comparison of the two reveals the influence of the CJTD on the lattice parameters. Replacing $\mathrm{Mn}^{3+}$ with $\mathrm{Fe}^{3+}$ leads, on average, to a $4.1 \%$ decrease in $a[a(\mathrm{Fe})<a(\mathrm{Mn})]$, a $2.8 \%$ increase in $b[b(\mathrm{Fe})>b(\mathrm{Mn})]$ and a $0.4 \%$ increase in $c$ $[c(\mathrm{Fe})>c(\mathrm{Mn})]$. The $A \mathrm{MnO}_{3}$ compounds have, on average, a

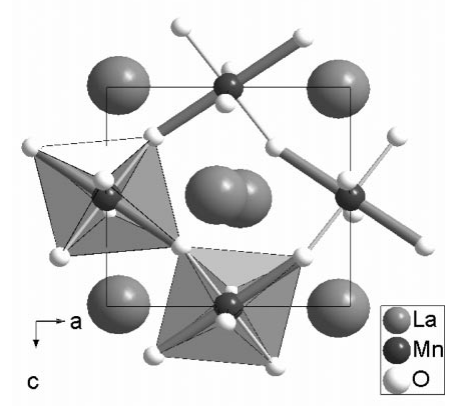

Figure 3

View down the $b$ axis (Pnma) of the crystal structure of $\mathrm{LaMnO}_{3}$, showing the $a c$-plane orbital ordering. Long $\mathrm{Mn}-\mathrm{O}$ bonds are depicted as thick black bonds, whereas thinner lines are used for the short and medium-length $\mathrm{Mn}-\mathrm{O}$ bonds.
$0.7 \%$ larger unit-cell volume than the corresponding members of the $A \mathrm{FeO}_{3}$ series. In the absence of tilting, the CJTD causes the $a$ and $c$ axes to expand equally, while the $b$ axis contracts. However, in the presence of $\mathrm{GdFeO}_{3}$-type tilting, we see a relatively large expansion of the $a$ axis and relatively little change in the length of the $c$ axis. The inequality in the expansion of the $a$ and $c$ axes originates from the in-phase tilting about the $b$ axis. The octahedral rotations cause the long $\mathrm{Mn}-\mathrm{O}$ bonds to align more closely with the $a$ axis than with the $c$ axis, as shown in Fig. 3. If we limit the tilting to rotations about the $b$ axis (tilt systems $a^{0} b^{-} a^{0}$ or $a^{0} b^{+} a^{0}$ ), we

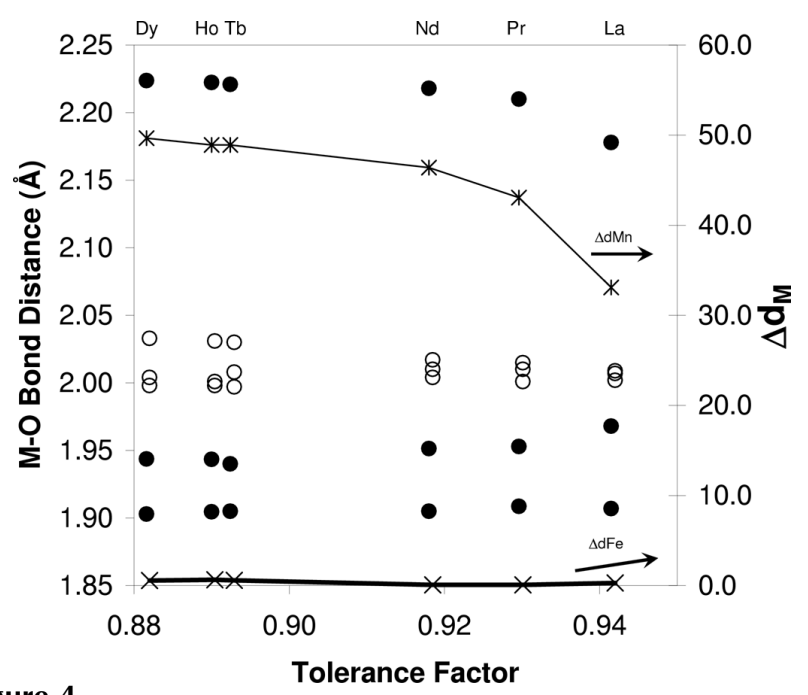

Figure 4

$M-\mathrm{O}$ distances versus tolerance factor for the $\mathrm{AMnO}_{3}$ and $A \mathrm{FeO}_{3}$ series. Filled symbols represent $M=\mathrm{Mn}$ and open symbols represent $M=\mathrm{Fe}$. Lines are shown to guide the eye.

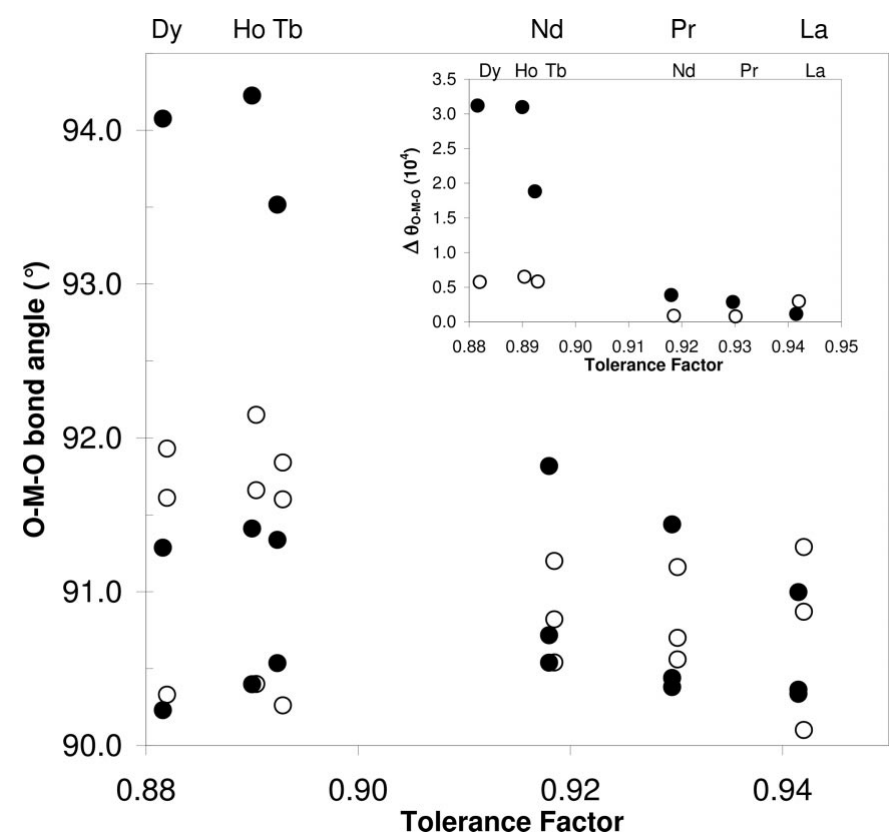

Figure 5

$\mathrm{O}-M-\mathrm{O}$ bond angles versus tolerance factor for $A M \mathrm{O}_{3}(M=\mathrm{Fe}$ and $\mathrm{Mn})$. Filled symbols represent $M=\mathrm{Mn}$ and open symbols represent $M=\mathrm{Fe}$. The inset shows $\Delta \theta_{\mathrm{O}-M-\mathrm{O}}\left(\times 10^{4}\right)$ versus tolerance factor for $A M \mathrm{O}_{3}(M=\mathrm{Fe}$ and $\mathrm{Mn})$. 
can express mathematically the effect of rotations on the response of the $a$ and $c$ axes to the development of a J-T distortion at the octahedral site. These relationships are

$$
\begin{aligned}
& a=2\left[d_{\text {long }} \cos (45-\varphi)+d_{\text {short }} \sin (45-\varphi)\right], \\
& c=2\left[d_{\text {long }} \sin (45-\varphi)+d_{\text {short }} \cos (45-\varphi)\right],
\end{aligned}
$$

where $d_{\text {long }}$ and $d_{\text {short }}$ are the longest and shortest $\mathrm{Mn}-\mathrm{O}$ bonds, respectively, and $\varphi$ is the rotation angle of the octahedra about the $b$ axis. When $\varphi$ is zero, the two cell edges are equal, but as $\varphi$ increases, the cosine terms gets larger while the sine terms get smaller, which necessarily leads to the condition that $a$ will expand in response to the CJTD, while the impact on $c$ will be smaller. In practice, this effect is quite pronounced.

The lattice distortion index $(D)$ is a measure of the distortion of the lattice from pseudocubic symmetry and is defined as

$$
D=(1 / 3) \sum_{n=1,3} 100\left[\left(a_{n}-\langle a\rangle\right) /\langle a\rangle\right]
$$

where $a_{n}$ is the individual lattice parameter converted to the length of the equivalent primitive unit cell $\left(a_{p} \simeq 4 \AA\right)\left(a / 2^{1 / 2}\right.$, $c / 2^{1 / 2}$ and $\left.b / 2\right)$ and $\langle a\rangle$ is the mean of the converted lattice parameters. The effect of the CJTD on the lattice parameters is illustrated in the plot of $D$ versus tolerance factor shown in Fig. 7. The trends show that, as expected, both octahedral tilting and the CJTD cause the lattice metrics to distort from cubic, but the effect is more pronounced for a CJTD.

The $A$-site cation displacement from the high-symmetry position (at the center of the eight surrounding octahedra) is significantly larger for the $R \mathrm{MnO}_{3}$ series than it is for the

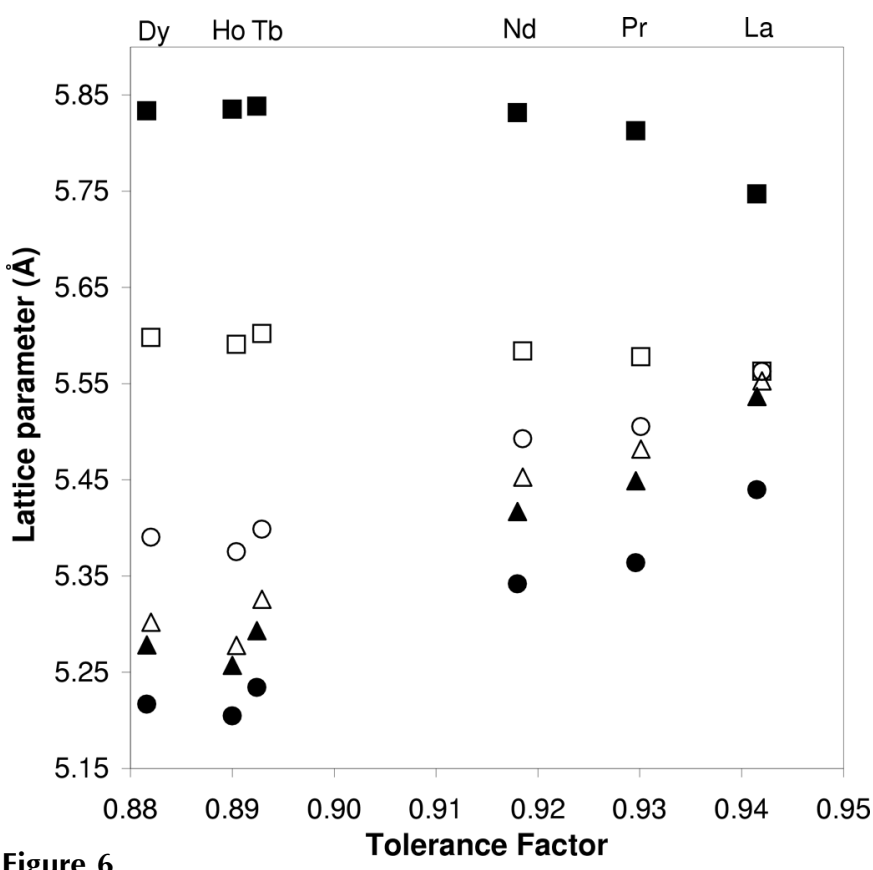

Figure 6

Filled symbol represent lattice parameters for $A \mathrm{MnO}_{3}$ compounds at room temperature. Open symbol represent lattice parameters for the corresponding $A \mathrm{FeO}_{3}$ compositions. Lattice parameters are represented by squares $(a)$, circles $\left(b / 2^{1 / 2}\right)$ and triangles $(c)$.
$\mathrm{RFeO}_{3}$ series, particularly in the $x$ direction, as evidenced in the $x$ coordinate of the $A$-site cation. This displacement occurs because the combination of octahedral tilting and the CJTD creates a cavity into which the $A$-site cation can shift. The $A$-site displacement from the high-symmetry position for $R M \mathrm{O}_{3}(M=\mathrm{Fe}$ and $\mathrm{Mn})$ compositions versus tolerance factor is shown in Fig. 8. The $R-\mathrm{O}$ bond lengths are surprisingly similar for the six closest distances, despite the distortion of the $\mathrm{MnO}_{6}$ octahedra. The majority of the $R-\mathrm{O}$ bonding is contained in the first six bonds, e.g. 80.4 and $82.0 \%$ of the $\mathrm{Nd}$ bond-valence sums of 2.96 v.u. $\left(\mathrm{NdMnO}_{3}\right)$ and $2.93 \mathrm{v} . \mathrm{u}$. $\left(\mathrm{NdFeO}_{3}\right)$ can be attributed to the first six $\mathrm{Nd}-\mathrm{O}$ bonds. All

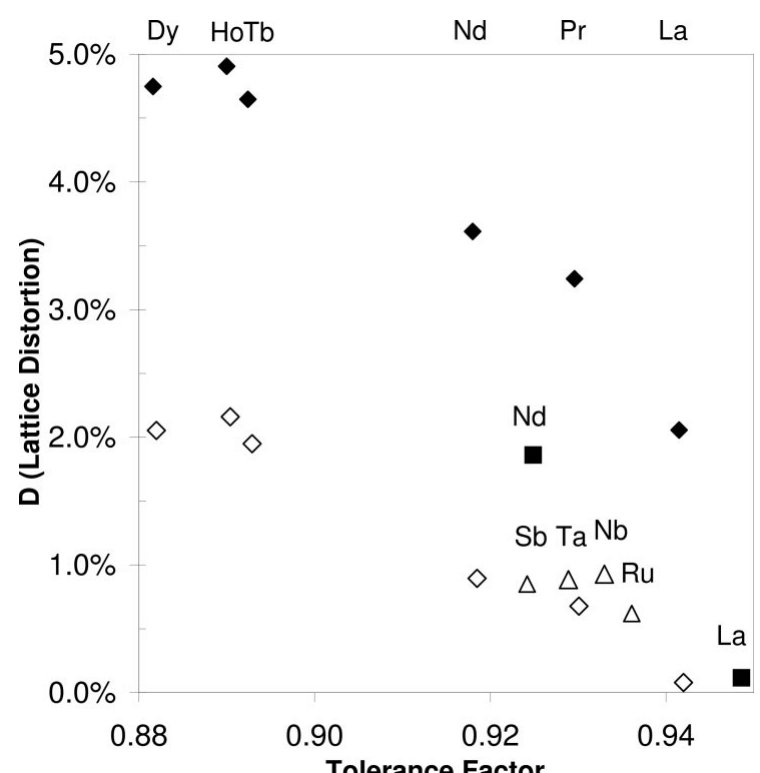

Figure 7

Tolerance Factor

Lattice distortion, $D$, for $A \mathrm{MnO}_{3}$ (filled diamonds), $A \mathrm{FeO}$ (open diamonds), $\mathrm{Ca}_{2}{\mathrm{Mn} M \mathrm{O}_{6}}_{6}(M=\mathrm{Sb}, \mathrm{Ta}, \mathrm{Nb}$ and $\mathrm{Ru}$ ) (open triangles) and $A_{2} \mathrm{MnGaO}_{6}(A=\mathrm{Nd}$ and La) (filled squares).

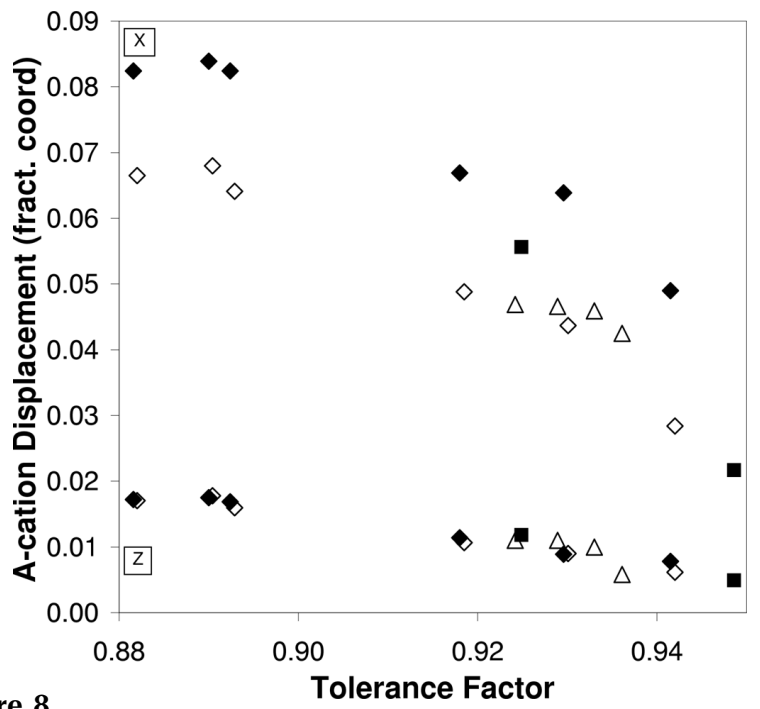

Figure 8

The $A$-site fractional displacement from the high-symmetry position in Pnma versus tolerance factor for $A \mathrm{MO}_{3}, A \mathrm{FeO}_{3}, \mathrm{Ca}_{2}{\mathrm{Mn} M \mathrm{O}_{6}}(M=\mathrm{Sb}$, $\mathrm{Ta}, \mathrm{Nb}$ and $\mathrm{Ru})$ and $A_{2} \mathrm{MnGaO}_{6}(A=\mathrm{La}$ and $\mathrm{Nd})$. The symbol description order is the same as that used in Fig. 7. 
twelve $\mathrm{Nd}-\mathrm{O}$ bond distances for $\mathrm{NdMnO}_{3}$ and $\mathrm{NdFeO}_{3}$ are shown in Table 3, illustrating the similarity in coordination environments for the $A$-site cations, even in the presence of the $\mathrm{J}-\mathrm{T}$ distortion. The $R-\mathrm{O}$ distances for several members of the $R M \mathrm{O}_{3}(M=\mathrm{Fe}$ and $\mathrm{Mn})$ series are shown in Fig. 9. The distribution of $R-\mathrm{O}$ distances shows very little perturbation in response to the CJTD.

In both series, the decreasing tolerance factor (increased tilting) leads to a larger distortion of the $\mathrm{O}-M-\mathrm{O}$ angles. However, this trend is much more pronounced in the $\mathrm{AMnO}_{3}$ series, as a result of the $\mathrm{J}-\mathrm{T}$ distortion. The Pnma perovskite structure becomes increasingly unstable as the octahedral tilting increases $(\tau<0.88)$, a trend that is exacerbated by the presence of a J-T cation on the octahedral site. Soft chemistry synthesis and/or high-pressure synthesis is required to stabilize the perovskite phase for manganites with an $A$-site ion smaller than $\mathrm{Tb}^{3+}$ (Alonso et al., 2000). A hexagonal structure type (space group $\mathrm{P6}_{3} \mathrm{~cm}$ ) with manganese in a trigonal-bipyramidal coordination is observed for $A \mathrm{MnO}_{3}$ compounds when the ionic radius of the $A$-site cation becomes too small $(\tau<0.88)$. Interestingly, for the same set of small rare-earth cations, the orthorhombic perovskite structure remains stable when the octahedral cation is $\mathrm{Fe}^{3+}$. As the tolerance factor continues to decrease, eventually a hexagonal structure (space group $\mathrm{Pb}_{3} / \mathrm{mmc}$ ), with trigonal-bipyramidal coordination about $\mathrm{Fe}$, is observed, as exemplified by $\mathrm{InFeO}_{3}(\tau=0.85$; Giaquinta et al., 1994). The destabilization of the perovskite structure when the $\mathrm{J}-\mathrm{T} \mathrm{Mn}^{3+}$ ion is present is likely to be at least partially related to the fact that trigonal-bipyramidal coordination does not produce an electronic degeneracy of the highest occupied molecular orbital (HOMO).

\section{Cation ordering, octahedral tilting and CJTDs in $A_{2} M M^{\prime} X_{6}$ systems}

Compounds with the composition $A_{2}{\mathrm{Cu} M \mathrm{O}_{6}}_{6}(A=\mathrm{Ba}$ and $\mathrm{Sr}$, and $M=\mathrm{W}$ and $\mathrm{Te}$ ) have a strong driving force for rock-salt cation ordering as a result of the oxidation-state difference of four between the $\mathrm{Cu}^{2+}$ and $\mathrm{W}^{6+} / \mathrm{Te}^{6+}$ ions. Additionally, these compounds exhibit out-of-phase tilting about the $c$ axis $\left(a^{0} a^{0} c^{-}\right)$. The long $\mathrm{Cu}-\mathrm{O}$ bonds, oriented parallel to the $c$ axis, induce a large tetragonal distortion. Lattice parameter ratios $c /\left(2^{1 / 2} a\right)$ for $\mathrm{Ba}_{2} \mathrm{CuMO}_{6}(\tau=1.042)$ are $1.098(M=\mathrm{W})$ and $1.092(M=\mathrm{Te})$, and for $\mathrm{Sr}_{2} \mathrm{CuMO}_{6}(\tau=0.983)$ are 1.096 $(M=\mathrm{W})$ and $1.102(M=\mathrm{Te})$. Octahedral distortion parameters $\Delta d_{\mathrm{Cu}}=70.8 \times 10^{-4}(M=\mathrm{W})$ and $85.0 \times 10^{-4}(M=$ Te) are observed for $A=\mathrm{Sr}$, whereas $\Delta d_{\mathrm{Cu}}=79.9 \times 10^{-4}$ $(M=\mathrm{W})$ and $84.8 \times 10^{-4}(M=\mathrm{Te})$ when $A=\mathrm{Ba}$. It is interesting to note that octahedral tilting occurs even in $\mathrm{Ba}_{2} \mathrm{CuWO}_{6}$ and $\mathrm{Ba}_{2} \mathrm{CuTeO}_{6}$, for which the tolerance factor is larger than unity. The tilt angle is somewhat larger in the $\mathrm{Sr}$ analogues, as the smaller tolerance factor would lead us to expect. A recent study has shown that in $\mathrm{Sr}_{2} \mathrm{CuWO}_{6}$ the octahedral tilting decreases upon heating, tending towards zero at a temperature of $\sim 873 \mathrm{~K}$ (Gateshki \& Igartua, 2003). It seems likely that similar transitions occur in the other three compounds at varying temperatures.
Table 3

$\mathrm{Nd}-\mathrm{O}$ bonds distances and valence for experimental crystal structures of $\mathrm{NdFeO}_{3}$ (BVS = 293 v.u.) and $\mathrm{NdMnO}_{3}$ (BVS = 296 v.u. .

\begin{tabular}{lllll}
\hline $\begin{array}{l}\mathrm{Nd}-\mathrm{O} \\
\text { distance } \\
\text { number }\end{array}$ & $\mathrm{NdFeO}_{3}(\AA)$ & $\begin{array}{l}\mathrm{NdFeO}_{3} \\
\mathrm{BVS}(\%)\end{array}$ & $\begin{array}{l}\mathrm{NdMnO} \\
(\AA)\end{array}$ & $\begin{array}{l}\mathrm{NdMnO}_{3} \\
\mathrm{BVS}(\%)\end{array}$ \\
\hline 1 & 2.34 & 18.0 & 2.35 & 17.6 \\
2 & 2.38 & 16.3 & 2.39 & 16.0 \\
3 & 2.38 & 16.3 & 2.39 & 16.0 \\
4 & 2.44 & 13.7 & 2.46 & 13.0 \\
5 & 2.60 & 8.9 & 2.60 & 8.9 \\
6 & 2.60 & 8.9 & 2.60 & 8.9 \\
7 & 2.73 & 6.3 & 2.63 & 8.3 \\
8 & 2.73 & 6.3 & 2.63 & 8.3 \\
9 & 3.17 & 1.9 & 3.16 & 2.0 \\
10 & 3.24 & 1.6 & 3.47 & 0.9 \\
11 & 3.42 & 1.0 & 3.55 & 0.7 \\
12 & 3.42 & 1.0 & 3.55 & 0.7 \\
\hline
\end{tabular}

In $\mathrm{La}_{2} \mathrm{CuSnO}_{6}$, the charge difference of two, combined with a large $\mathrm{J}-\mathrm{T}$ distortion about the $\mathrm{Cu}^{2+}$ ion, and a significant octahedral-tilting distortion $(\tau=0.917)$, stabilizes a layered ordering of octahedral-site cations. Layered octahedral-site ordering is very unusual. Its stability appears to be closely coupled with the size of the octahedral-tilting distortion. In this structure, the long $\mathrm{Cu}-\mathrm{O}$ bonds are all aligned effectively in a single direction (along the $a$ axis of $P 2_{1} / m$ ), similar to the $\mathrm{Ba}_{2} \mathrm{CuWO}_{6}$ structure. Additional layered compounds of composition $A_{2} \mathrm{CuSnO}_{6}(A=\mathrm{Pr}$ and $\mathrm{Nd})$ and $\mathrm{La}_{2} \mathrm{CuZrO}_{6}$ have been synthesized under high-pressure high-temperature conditions (Azuma et al., 1998).

On going from $\mathrm{La}_{2} \mathrm{CuSnO}_{6}(\tau=0.917)$ to $\mathrm{La}_{2} \mathrm{CuTiO}_{6}$ ( $\tau=0.945)$ (Palacin et al., 1993), the difference in the radii of the octahedral cations actually increases $\left(r_{\mathrm{Ti}}=0.75 \AA, r_{\mathrm{Sn}}=\right.$ $0.83 \AA$ and $r_{\mathrm{Cu}}=0.87 \AA$ ), yet the long-range cation ordering disappears, as does the CJTD. The octahedral site contains a

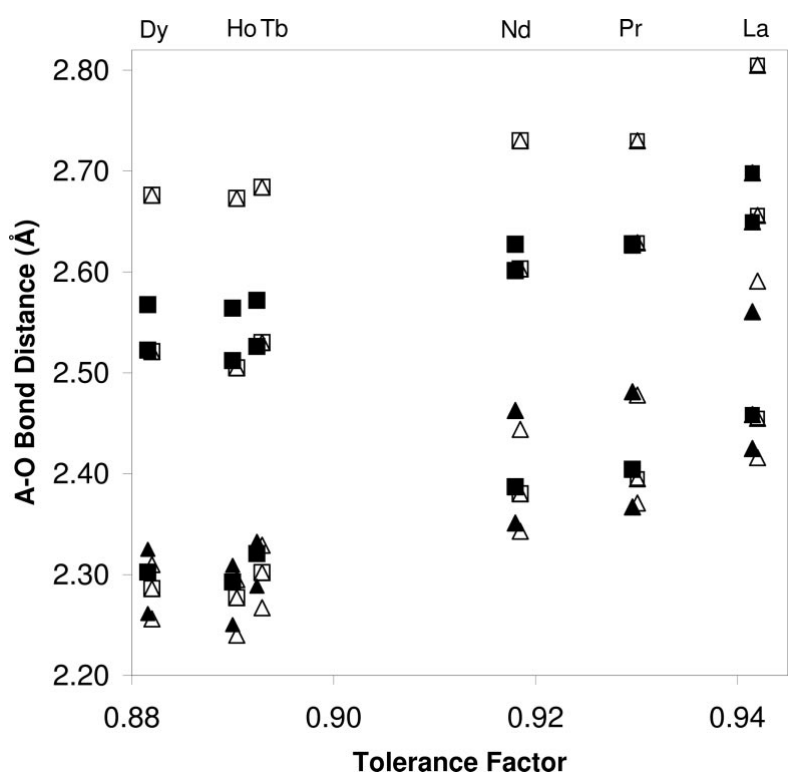

Figure 9

$R-\mathrm{O}$ bond distances (eight shortest) for $R \mathrm{MnO}_{3}$ (filled) and $R \mathrm{FeO}_{3}$ (open) as a function of tolerance factor. Triangles indicate a multiplicity of one, squares a multiplicity of two (see Table 3). 
random mixture of $\mathrm{Cu}^{2+}$ and $\mathrm{Ti}^{4+}$ with a symmetric distribution of $M-\mathrm{O}$ bond distances [ $2 \times 2.033$ (4), $2 \times 2.022$ (4) and $2 \times 2.007$ (1) $\left.\AA ; \Delta d_{\mathrm{Cu}}=0.27 \times 10^{-4}\right]$. This example illustrates the sensitivity of both the orbital and the cation ordering to changes in octahedral tilting.

The crystal structures of $A_{2} \mathrm{MnGaO}_{6}(A=\mathrm{La}$ and Nd) were determined from Rietveld refinement of high-resolution neutron powder diffraction data (Cussen et al., 2001). Octahedrally symmetric $\mathrm{Ga}^{3+}$ and the $\mathrm{J}-\mathrm{T}$ active $\mathrm{Mn}^{3+}$ ions are disordered over a single crystallographic site (as in $\mathrm{La}_{2} \mathrm{CuTiO}_{6}$ ). Surprisingly, the refinements show that the coordination of the disordered octahedral site in the two compounds is quite different. $\mathrm{Nd}_{2} \mathrm{MnGaO}_{6}$ has a considerable CJTD $\left(\Delta d=12.7 \times 10^{-4}\right.$, albeit reduced compared with that of $A \mathrm{MnO}_{3}$ ), with $M-\mathrm{O}$ bond lengths of $1.9703(2)(\times 2)$, $2.1011(8)(\times 2)$ and $1.9350(8) \AA(\times 2)$. In contrast, the octahedral-site coordination in $\mathrm{La}_{2} \mathrm{MnGaO}_{6}$ is symmetric, with $M-\mathrm{O}$ bond lengths of $1.9898(6)(\times 2), 1.982(2)(\times 2)$ and $1.978(2) \AA(\times 2)\left(\Delta d=0.06 \times 10^{-4}\right)$. This conformation does not necessarily imply the complete absence of a J-T distortion in $\mathrm{La}_{2} \mathrm{GaMnO}_{6}$; rather, it is more likely that $\mathrm{J}-\mathrm{T}$ distortions are present locally but the orientation of these distortions is disordered. Bond-angle $(\mathrm{O}-\mathrm{Mn}-\mathrm{O})$ distortion parameters in $\mathrm{La}_{2} \mathrm{MnGaO}_{6}$ and $\mathrm{Nd}_{2} \mathrm{MnGaO}_{6}\left(\Delta \theta_{X M X}=0.37 \times 10^{-4}\right.$ and $0.16 \times 10^{-4}$ ) are comparable to those in $\mathrm{LaMnO}_{3}$ and $\mathrm{NdMnO}_{3}\left(\Delta \theta_{X B X}=0.11 \times 10^{-4}\right.$ and $\left.0.39 \times 10^{-4}\right)$. While it is true that the $A$-site cations lanthanum and neodymium have slightly different 12 -coordinate ionic radii (1.50 and $1.41 \AA$, respectively; Shannon, 1976), the basic characteristics of $\mathrm{Nd}-$ $\mathrm{O}$ and $\mathrm{La}-\mathrm{O}$ bonding are expected to be similar. Thus the presence of orbital ordering and a CJTD in $\mathrm{Nd}_{2} \mathrm{GaMnO}_{6}$ but not in $\mathrm{La}_{2} \mathrm{MnGaO}_{6}$ appears to originate from the larger magnitude of octahedral tilting induced by the smaller $\mathrm{Nd}^{3+}$ ion.

In order to investigate further the link between orbital order, cation order and octahedral tilting, consider the crystal chemistry of the $A_{2}{\mathrm{Mn} M \mathrm{O}_{6}}_{6}(A=\mathrm{Ca}$ and $\mathrm{Sr}$, and $M=\mathrm{Ru}, \mathrm{Sb}$, $\mathrm{Ta}$ and $\mathrm{Nb}$ ) double perovskites. We have recently used neutron powder diffraction to characterize six of these compounds structurally, namely $A_{2}{\mathrm{Mn} M \mathrm{O}_{6}}(A=\mathrm{Ca}$ and $\mathrm{Sr}$, and $M=\mathrm{Ru}, \mathrm{Sb}$ and $\mathrm{Nb}$ ). The details are published elsewhere (Lufaso et al., 2004). Previously, Woodward (1997c) investigated the structures of $\mathrm{Sr}_{2} \mathrm{MnTaO}_{6}$ and $\mathrm{Ca}_{2} \mathrm{MnTaO}_{6}$ using $\mathrm{X}$-ray powder diffraction. Long-range cation order is not observed in any of the eight compositions. However, comparisons with $A_{2} \mathrm{Fe} M \mathrm{O}_{6}$ perovskites suggest that longrange order in one dimension, and probably considerable short- and medium-range order, are present when $M=\mathrm{Sb}$. Size considerations suggest that similar ordering may also exist when $M=\mathrm{Ru}$. All four $\mathrm{Sr}_{2}{\mathrm{Mn} M \mathrm{O}_{6}}_{(}(M=\mathrm{Sb}, \mathrm{Ru}$, Ta and $\mathrm{Nb})$ compositions crystallize with $14 / \mathrm{mcm}$ space-group symmetry and show rotations of the octahedra about the $c$ axis $\left(a^{0} a^{0} c^{-}\right.$octahedral tilting). This behavior is very similar to that of the ordered $A_{2}{\mathrm{Cu} M \mathrm{O}_{6}}_{6}$ compounds. While the long-range orbital ordering is limited, there is a clear sign of a small CJTD and orbital ordering in $\mathrm{Sr}_{2} \mathrm{MnRuO}_{6}$ and $\mathrm{Sr}_{2} \mathrm{MnSbO}_{6}$. On the other hand, there is little evidence for orbital ordering in
$\mathrm{Sr}_{2} \mathrm{MnTaO}_{6}$ or $\mathrm{Sr}_{2} \mathrm{MnNbO}_{6}$. Replacing $\mathrm{Sr}^{2+}$ with the smaller $\mathrm{Ca}^{2+}$ decreases the tolerance factor and increases the tilting, so

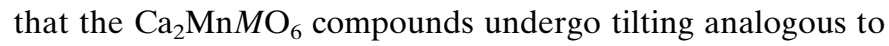
that seen in $A \mathrm{MnO}_{3}$ and $A \mathrm{FeO}_{3}\left(a^{-} b^{+} a^{-}\right.$octahedral tilting $)$ and crystallize with Pnma space-group symmetry. The increased octahedral tilting appears to destabilize the orbital ordering and CJTD seen for $\mathrm{Sr}_{2} \mathrm{MnRuO}_{6}$ and $\mathrm{Sr}_{2} \mathrm{MnSbO}_{6}$. Tolerance factors, $M-\mathrm{O}$ bond lengths, distortion parameters, lattice parameters and orientations of the long $M-\mathrm{O}$ bonds are given in Tables 4 and 5. Note that in all of the $A_{2} \mathrm{Mn}^{5+} \mathrm{O}_{6}$ ( $A=\mathrm{Ca}$ and $\mathrm{Sr}$ ) compounds studied the octahedral cations are disordered.

\section{Orbital ordering and cation ordering}

The orbital-ordering schemes observed in $A \mathrm{CuF}_{3}$ ( $a$ - and $d$-type) and $A \mathrm{MnO}_{3}$ (d-type) perovskites are shown in Figs. 10 $(a)$ and $10(b)$ (neglecting octahedral-tilting distortions). On going from a ternary to an ordered $A_{2} M M^{\prime} X_{6}$ perovskite, several arrangements are possible. The simplest pattern is to replace every other $\mathrm{J}-\mathrm{T}$ active cation with a symmetric cation in a 1:1 rock-salt ordered pattern, as shown in Fig. 10(c). This is the orbital-ordering scheme adopted by $A_{2} \mathrm{Cu} M^{6+} \mathrm{O}_{6}$ compounds. Note that all of the long $M-X$ bonds are oriented in the same direction. This cooperative pattern of $\mathrm{J}-\mathrm{T}$ distortions along a single axis is a ferrodistortive orbital ordering, as opposed to the $a c$-plane antiferrodistortive orbital ordering seen in $\mathrm{LaMnO}_{3}$ and $\mathrm{KCuF}_{3}$ (Battle et al., 2002).
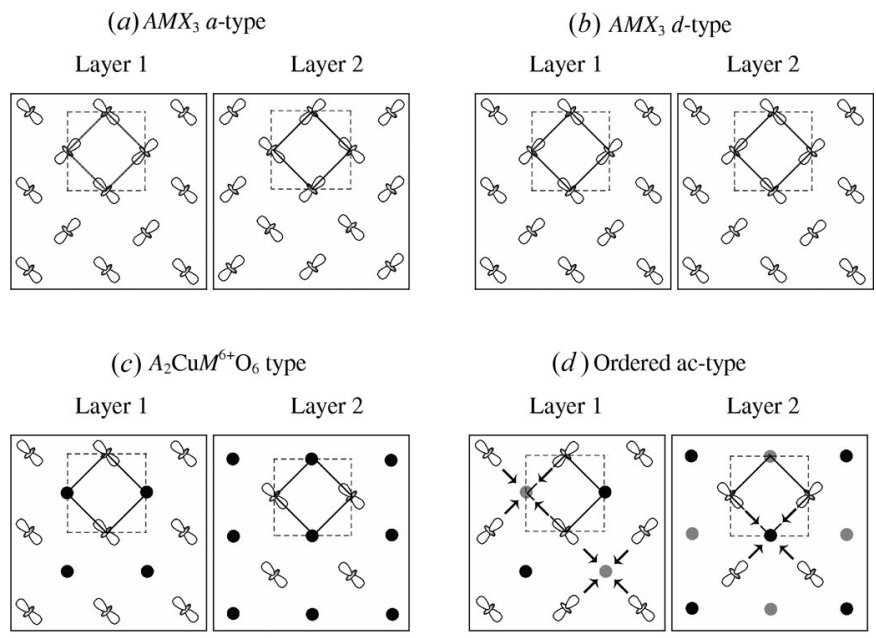

(e) Pseudo $\mathrm{NdSrMn}_{2} \mathrm{O}_{6}$ (rock salt ordering) type
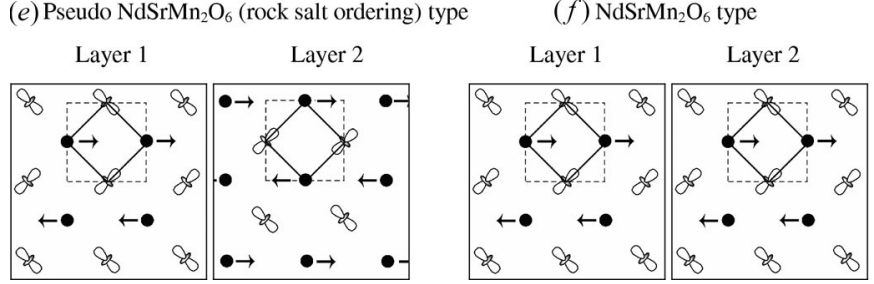

Figure 10

Orbital-ordering schemes in $(a)-(b)$ ternary $A M X_{3}$ perovskites and $(c)$ ( $f$ ) quaternary ordered $A_{2} M M^{\prime} X_{6}$ perovskites. The solid lines indicate the simple cubic perovskite unit cell, while the dotted line shows the $a$ and $c$ axes of the Pnma unit cell. For clarity, only the octahedral ions are shown. 
Table 4

Lattice parameters, tilt system, $M-\mathrm{O}$ bond distances, octahedral distortion parameter, space group, tolerance factor and reference for $\mathrm{Sr}_{2} M M^{\prime} \mathrm{O}_{6}\left(M=\mathrm{Mn}\right.$ and $\mathrm{Fe}$, and $M^{\prime}=\mathrm{Nb}, \mathrm{Ta}, \mathrm{Ru}$ and $\left.\mathrm{Sb}\right)$.

\begin{tabular}{|c|c|c|c|c|}
\hline & $\mathrm{Sr}_{2} \mathrm{FeRuO}_{6} \dagger$ & $\mathrm{Sr}_{2} \mathrm{MnRuO}_{6}$ & $\begin{array}{l}\mathrm{Sr}_{2} \mathrm{FeSbO}_{6} \\
+\neq\end{array}$ & $\mathrm{Sr}_{2} \mathrm{MnSbO}_{6}$ \\
\hline$a(\AA)$ & $5.5379(3)$ & $5.45459(1)$ & $5.6132(5)$ & $5.5553(2)$ \\
\hline$b(\AA)$ & $5.5429(3)$ & - & $5.5973(5)$ & - \\
\hline$c(\AA)$ & $7.8772(1)$ & $7.9340(2)$ & $7.9036(7)$ & $8.0548(3)$ \\
\hline Tilt system & $a^{-} b^{-} a^{-}$ & $a^{0} a^{0} c^{-}$ & $a^{-} b^{+} a^{-}$ & $a^{0} a^{0} c^{-}$ \\
\hline$M-\mathrm{O}(\AA)$ & $1.97(2) \times 2$ & $\begin{array}{l}1.98349(4) \\
\times 2\end{array}$ & $2.006(9) \times 2$ & $\begin{array}{l}2.0137(1) \\
\times 2\end{array}$ \\
\hline$M-\mathrm{O}(\AA)$ & $1.97(2) \times 2$ & $\begin{array}{c}1.9429(1) \\
\times 4\end{array}$ & $\begin{array}{l}1.995(10) \times \\
2\end{array}$ & $\begin{array}{l}1.9781(3) \\
\times 4\end{array}$ \\
\hline$M-\mathrm{O}(\AA)$ & $1.97(3) \times 2$ & - & $\begin{array}{l}1.994(14) \times \\
2\end{array}$ & - \\
\hline$\Delta d\left(\times 10^{-4}\right)$ & 0.0 & 0.96 & 0.07 & 0.71 \\
\hline$D(\%) \S$ & 0.24 & 1.25 & 0.16 & 1.11 \\
\hline Symmetry & $I 2 / c$ & $I 4 / \mathrm{mcm}$ & $P 2_{1} / n$ & $I 4 / \mathrm{mcm}$ \\
\hline $\begin{array}{l}\text { Tolerance } \\
\text { factor }\end{array}$ & 0.987 & 0.990 & 0.978 & 0.977 \\
\hline \multirow[t]{2}{*}{ Reference } & $\begin{array}{l}\text { Battle et al. } \\
\text { (1989) }\end{array}$ & $\begin{array}{l}\text { Lufaso et al. } \\
\quad(2004)\end{array}$ & $\begin{array}{l}\text { Cussen, et al. } \\
\text { (1997) }\end{array}$ & $\begin{array}{l}\text { Lufaso et al. } \\
\quad(2004)\end{array}$ \\
\hline & $\mathrm{Sr}_{2} \mathrm{FeTaO}_{6}$ & $\mathrm{Sr}_{2} \mathrm{MnTaO}_{6}$ & $\mathrm{Sr}_{2} \mathrm{FeNbO}_{6} \uparrow$ & $\mathrm{Sr}_{2} \mathrm{MnNbO}_{6}$ \\
\hline$a(\AA)$ & $5.6204(3)$ & $5.6135(1)$ & $5.6084(9)$ & $5.6119(6)$ \\
\hline$b(\AA)$ & $5.6161(3)$ & - & $5.6082(9)$ & - \\
\hline$c(\AA)$ & $7.9266(3)$ & $7.9510(3)$ & $7.9642(1)$ & 7.927 (1) \\
\hline Tilt system & $\begin{array}{l}a^{-} b^{+} a^{-} \\
1.9984(4)\end{array}$ & $a^{0} a^{0} c^{-}$ & $a^{-} b^{+} a^{-}$ & $\begin{array}{l}a^{0} a^{0} c^{-} \\
1.9818 \text { (4) }\end{array}$ \\
\hline$M-\mathrm{O}(\AA)$ & $\times 2$ & $1.988 \times 2$ & - & $\begin{array}{c}\times 2 \\
1.9937(4)\end{array}$ \\
\hline$M-\mathrm{O}(\AA)$ & $1.994(5) \times 2$ & $1.996 \times 4$ & - & $\times 4$ \\
\hline$M-\mathrm{O}(\AA)$ & $1.988(5) \times 2$ & - & - & - \\
\hline$\Delta d\left(\times 10^{-4}\right)$ & 0.05 & 0.04 & - & 0.08 \\
\hline$D(\%)$ & 0.11 & 0.07 & 0.18 & 0.05 \\
\hline Symmetry & Pbnm & $I 4 / \mathrm{mcm}$ & Pbnm & $I 4 / \mathrm{mcm}$ \\
\hline \multicolumn{5}{|l|}{ Tolerance } \\
\hline Reference & $\begin{array}{l}\text { Cussen et al. } \\
\quad(1997)\end{array}$ & $\begin{array}{c}\text { Woodward } \\
(1997 c)\end{array}$ & $\begin{array}{l}\text { Tezuka et al. } \\
\quad(2000)\end{array}$ & $\begin{array}{l}\text { Lufaso et al. } \\
\quad(2004)\end{array}$ \\
\hline
\end{tabular}

$\dagger$ Monoclinic angles are $\beta=90.11(1)^{\circ}$ for $\mathrm{Sr}_{2} \mathrm{FeRuO}_{6}$ and $\beta=90.01(1)^{\circ}$ for $\mathrm{Sr}_{2} \mathrm{Fe}$ $\mathrm{SbO}_{6}$. \$ The $\mathrm{Sb}-\mathrm{O}$ bond lengths are $1.979(9) \times 2, \quad 1.972(9) \times 2$ and $1.989(14) \times 2 \AA$, with $B$-site occupancies $(S)$ of 0.795 (6) and 0.205 (6) for a long-range order parameter of $59 \%$, using the formula $2(S-1) \times 100 \%$. $\S$ The lattice distortion index $(D)$ is strictly valid for orthogonal unit cells; however, the monoclinic angles are near $90^{\circ}$ and thus $D$ is included for comparison. The crystal structure of $\mathrm{Sr}_{2} \mathrm{FeNbO}_{6}$ was refined from powder X-ray diffraction data; bond lengths are not included for this compound because their accuracy is questionable.

Why does the introduction of cation order lead to a reorientation of the orbital ordering? To understand the link between cation ordering and orbital ordering, consider the hypothetical structure that would result if $a c$-plane orbital ordering and rock-salt cation ordering were superimposed. The result is shown in Fig. 10(d). We can immediately see that this arrangement is unfavorable because, in order to maintain connectivity, the $M^{\prime}-X$ bonds are compressed at one-half of the symmetric $M^{\prime}$ cations and elongated at the remaining $M^{\prime}$ sites. Thus there are two crystallographically and chemically distinct sites for the $M^{\prime}$ cations, violating Pauling's (1929) rule of parsimony. A search of the literature revealed no compounds that adopt such an arrangement. This unfavorable arrangement can be avoided if one reverses the orientation of the occupied $e_{g}$ orbitals in every other row, as shown in Fig. 10(e). In this arrangement, the long $M-X$ bonds are
Table 5

Lattice parameters, tilt system, $M-\mathrm{O}$ bond distances, octahedral distortion parameter, space group, tolerance factor and reference for $\mathrm{Ca}_{2} M M^{\prime} \mathrm{O}_{6}\left(M=\mathrm{Mn}\right.$ and $\mathrm{Fe}$, and $M^{\prime}=\mathrm{Nb}, \mathrm{Ta}, \mathrm{Ru}$ and $\left.\mathrm{Sb}\right)$.

\begin{tabular}{|c|c|c|c|c|}
\hline & $\mathrm{Ca}_{2} \mathrm{FeRuO}_{6}$ & $\mathrm{Ca}_{2} \mathrm{MnRuO}_{6}$ & $\mathrm{Ca}_{2} \mathrm{FeSbO}_{6}+\neq$ & $\mathrm{Ca}_{2} \mathrm{MnSbO}_{6}$ \\
\hline$a(\AA)$ & - & $5.3346(3)$ & $5.4371(1)$ & $5.4591(4)$ \\
\hline$b(\AA)$ & - & $5.4207(3)$ & 5.5259 (1) & $5.5549(5)$ \\
\hline$c(\AA)$ & - & $7.5757(4)$ & $7.7340(2)$ & $7.6941(6)$ \\
\hline Tilt system & - & $a^{-} b^{+} a^{-}$ & $a^{-} b^{+} a^{-}$ & $a^{-} b^{+} a^{-}$ \\
\hline $\begin{array}{l}M-\mathrm{O}(\AA) \\
\quad\left(a b_{1}\right) \times 2\end{array}$ & - & $1.956(2)$ & $1.98(2)$ & $2.011(3)$ \\
\hline $\begin{array}{l}M-\mathrm{O}(\AA) \\
\left(a b_{2}\right) \times 2\end{array}$ & - & $1.953(2)$ & $1.97(2)$ & $2.003(3)$ \\
\hline $\begin{array}{l}M-\mathrm{O}(\AA) \\
(c) \times 2\end{array}$ & - & $1.9429(6)$ & $1.95(2)$ & $1.9858(9)$ \\
\hline$\Delta d\left(\times 10^{-4}\right)$ & - & 0.08 & 0.40 & 0.28 \\
\hline$D(\%) \S$ & - & 0.62 & 0.60 & 0.85 \\
\hline Symmetry & - & Pbnm & $P 2_{1} / n$ & Pbnm \\
\hline $\begin{array}{l}\text { Tolerance } \\
\text { factor }\end{array}$ & - & 0.936 & 0.924 & 0.925 \\
\hline Reference & - & $\begin{array}{l}\text { Lufaso et al. } \\
\quad(2004)\end{array}$ & $\begin{array}{l}\text { Lee } \text { et al. } \\
\quad(1997)\end{array}$ & $\begin{array}{l}\text { Lufaso et al. } \\
\quad(2004)\end{array}$ \\
\hline & $\mathrm{Ca}_{2} \mathrm{FeTaO}_{6}$ & $\mathrm{Ca}_{2} \mathrm{MnTaO}_{6}$ & $\mathrm{Ca}_{2} \mathrm{FeNbO}_{6}$ & $\mathrm{Ca}_{2} \mathrm{MnNbO}_{6}$ \\
\hline$a(\AA)$ & $5.4498(1)$ & $5.4574(1)$ & $5.4480(4)$ & $5.4530(4)$ \\
\hline$b(\AA)$ & $5.5482(1)$ & $5.5664(1)$ & $5.5517(4)$ & $5.5635(4)$ \\
\hline$c(\AA)$ & $7.7591(2)$ & $7.7166(2)$ & $7.7612(5)$ & $7.6996(5)$ \\
\hline $\begin{array}{l}\text { Tilt system } \\
M-\mathrm{O}(\AA)\end{array}$ & $a^{-} b^{+} a^{-}$ & $a^{-} b^{+} a^{-}$ & $a^{-} b^{+} a^{-}$ & $a^{-} b^{+} a^{-}$ \\
\hline $\begin{array}{c}\left(a b_{1}\right) \times 2 \\
M-\mathrm{O}(\AA)\end{array}$ & - & - & $1.91(2)$ & $2.008(2)$ \\
\hline $\begin{array}{c}\left(a b_{2}\right) \times 2 \\
M-\mathrm{O}(\AA)\end{array}$ & - & - & $1.93(2)$ & $2.005(2)$ \\
\hline (c) $\times 2$ & - & - & $1.94(2)$ & $1.9807(7)$ \\
\hline$\Delta d\left(\times 10^{-4}\right)$ & - & - & 0.42 & 0.37 \\
\hline$D(\%) \S$ & 0.65 & 0.88 & 0.68 & 0.93 \\
\hline $\begin{array}{l}\text { Symmetry } \\
\text { Tolerance }\end{array}$ & $P 2_{1} / n$ & Pbnm & $P 2_{1} / n$ & Pbnm \\
\hline factor & 0.931 & 0.931 & $\begin{array}{l}0.933 \\
\text { Chakhmoura- } \\
\quad \text { dian \& }\end{array}$ & 0.933 \\
\hline Reference & $\begin{array}{l}\text { Woodward } \\
\quad(1997 c)\end{array}$ & $\begin{array}{l}\text { Woodward } \\
\quad(1997 c)\end{array}$ & $\begin{array}{l}\text { Mitchell } \\
\text { (1998) }\end{array}$ & $\begin{array}{l}\text { Lufaso et al. } \\
\quad(2004)\end{array}$ \\
\hline
\end{tabular}

$\dagger$ The $\mathrm{Sb}-\mathrm{O}$ bond lengths are $2.04(2) \times 2,2.03(2) \times 2$ and $2.01(2) \times 2 \AA$. $\ddagger$ The monoclinic angles are $\beta=89.97(1)^{\circ}$ for $\mathrm{Ca}_{2} \mathrm{FeSbO}_{6}, \beta=90.11(2)^{\circ}$ for $\mathrm{Ca}_{2} \mathrm{FeNbO}_{6}$ and $\beta=90.072(4)^{\circ}$ for $\mathrm{Ca}_{2} \mathrm{FeTaO}_{6}$. $\S$ The lattice distortion index $(D)$ is strictly valid for orthogonal unit cells; however, the monoclinic angles are near $90^{\circ}$ and thus $D$ is included for comparison. T The $\mathrm{Nb}-\mathrm{O}$ bond lengths are 2.03 (2), 2.10 (2) and 2.10 (2) $\AA$.

stabilized by a shift of the symmetric $M^{\prime} X_{6}$ octahedra, as indicated by the arrows in Fig. 10(e). However, notice that $M^{\prime} X_{6}$ octahedra in neighboring layers shift in opposite directions, thus creating a lattice strain that is energetically unfavorable. On the other hand, if the cation ordering is modified to the chain type (see Fig. 1), the symmetric $M^{\prime} X_{6}$ octahedra in the neighboring layers can shift in the same direction, as shown in Fig. 10(f). This is the CJTD and orbital-ordering scheme reported for $R A \mathrm{Mn}^{3+} \mathrm{Mn}^{4+} \mathrm{O}_{6}$ compounds, such as $\mathrm{NdSrMn}_{2} \mathrm{O}_{6}$ (Woodward et al., 1999). Clearly, the cation- and orbital-ordering possibilities are diverse but closely linked.

\section{Discussion}

The J-T theorem states that a distortion of the octahedra should occur when there is a partially occupied degenerate set 
of HOMOs. However, the theorem specifies neither the magnitude of the distortion, $\Delta d_{M}$, nor the long-range pattern of distortions in an extended solid. Ternary perovskites containing a J-T ion exhibit a large CJTD, with $\mathrm{Cu}^{2+}$ octahedra exhibiting a much larger distortion than $\mathrm{Mn}^{3+}$ octahedra. In $\mathrm{RbCuF}_{3}$, the presence of the $\mathrm{Rb}$ cation causes a lengthening of the longest and weakest $\mathrm{Cu}-\mathrm{F}$ bonds, which results in a larger distortion of the octahedra than is observed in $\mathrm{KCuF}_{3}$. Ordered perovskites containing $\mathrm{Cu}^{2+}$, i.e. $A_{2} \mathrm{Cu} M \mathrm{O}_{6}$ ( $A=\mathrm{Ba}$ and $\mathrm{Sr}$, and $M=\mathrm{W}$ and $\mathrm{Te}$ ), contain distorted $\mathrm{CuO}_{6}$ octahedra with sizes and shapes similar to those observed for $\mathrm{RbCuF}_{3}$. Fig. 10(c) shows that the CJTD and orbital ordering in these quarternary ordered perovskites can be obtained from the ternary $\mathrm{KCuF}_{3}$ pattern by replacing $50 \%$ of the $\mathrm{Cu}^{2+}$ centered octahedra with symmetric $M^{6+}$-centered octahedra.

In the $R \mathrm{MnO}_{3}$ series, increased octahedral tilting leads to an increase in the magnitude of the CJTD. This effect can be seen from the increase in $\Delta d_{M}$ that occurs as the tolerance factor decreases across the $R \mathrm{MnO}_{3}$ series. Increased octahedral bond-angle distortion of the $X-M-X$ bond angles also occurs in the $R \mathrm{MnO}_{3}$ series for the smaller rare-earth cations. In contrast, no increase in $\Delta \theta_{X M X}$ is observed with increased tilting in the corresponding $A \mathrm{FeO}_{3}$ series. Octahedral tilting in $\mathrm{NaCuF}_{3}$ is also accompanied by a strong distortion of the $\mathrm{F}-$ $\mathrm{Cu}-\mathrm{F}$ bond angles, with an average $\Delta \theta_{X M X}$ of $36.6 \times 10^{-4}$.

The $\mathrm{Sr}_{2}{\mathrm{Mn} M \mathrm{O}_{6}}_{6}(M=\mathrm{Ru}$ and $\mathrm{Sb})$ series have $c /\left(2^{1 / 2} a\right)$ ratios of 1.028 and 1.025 , respectively, and $M-\mathrm{O}$ bond distances as shown in Table 4. Their comformations imply that local J-T distortions are oriented along the $c$ axis. The reduction (compared with those of $A \mathrm{MnO}_{3}$ ) in $\Delta d_{M}$ values is due in part to dilution of the $\mathrm{J}-\mathrm{T}$ ion with the symmetric ion. It seems likely that medium-range cation order, proposed as extended regions of cation ordering along the $c$ axis, stabilizes the CJTD in $\mathrm{Sr}_{2} \mathrm{MnMO}_{6}(M=\mathrm{Ru}$ and $\mathrm{Sb})$. Local regions of cation order in $\mathrm{Sr}_{2} \mathrm{MnRuO}_{6}$ were reported from TEM studies (Goldberger et al., 2004). Although it is difficult to know the extent of cation order on the local scale in $\mathrm{Sr}_{2} \mathrm{MnMO}_{6}(M=\mathrm{Nb}$ and Ta), we suspect that these compounds possess enough short-range cation order for the situation to be described as intermediate between a completely random distribution and the mediumrange order suggested for $\mathrm{Sr}_{2}{\mathrm{Mn} M \mathrm{O}_{6}}_{(}(M=\mathrm{Ru}$ and $\mathrm{Sb})$. This distribution apparently destabilizes the CJTD, as no evidence for a CJTD can be found in $\mathrm{Sr}_{2} \mathrm{MnMO}_{6}(M=\mathrm{Nb}$ and Ta). When the two octahedral-site cations have the same oxidation state and similar radii, as is the case for $\mathrm{La}_{2} \mathrm{MnGaO}_{6}$ and $\mathrm{Nd}_{2} \mathrm{MnGaO}_{6}$, it is likely that the cation distribution is nearly random. In this case, the magnitude of the CJTD appears to increase with increased octahedral tilting.

Replacing $\mathrm{Sr}^{2+}$ with $\mathrm{Ca}^{2+}$ clearly reduces the tolerance factor and increases the octahedral tilting. Within the $A_{2}{\mathrm{Mn} M \mathrm{O}_{6}}_{(}(A=\mathrm{Sr}$ and $\mathrm{Ca}$, and $M=\mathrm{Ru}, \mathrm{Sb}, \mathrm{Nb}$ and $\mathrm{Ta})$ series this process leads to a change of tilt system, from $a^{0} a^{0} c^{-}$to $a^{-} b^{+} a^{-}$. Unlike the $A_{2} \mathrm{MnGaO}_{6}$ and $R \mathrm{MnO}_{3}$ compounds, where increased octahedral tilting stabilizes a larger CJTD, it appears that, in this case, the increased octahedral-tilting distortion actually destabilizes orbital ordering. This behavior can probably be seen most clearly from a comparison of the lattice parameters of $\mathrm{Sr}_{2}{\mathrm{Mn} M \mathrm{O}_{6}}_{6}$ and $\mathrm{Ca}_{2} \mathrm{MnMO}_{6}$ with those of $\mathrm{Sr}_{2} \mathrm{Fe} M \mathrm{O}_{6}$ and $\mathrm{Ca}_{2} \mathrm{Fe}_{2} \mathrm{O}_{6}$. The lattice-distortion indices for the $\mathrm{Ca}_{2} \mathrm{MnMO}_{6}$ compounds are only slightly larger than those for $\mathrm{Ca}_{2} \mathrm{Fe} M \mathrm{O}_{6}(M=\mathrm{Ru}, \mathrm{Sb}, \mathrm{Nb}$ and $\mathrm{Ta})$, whereas the differences are much more pronounced for $\mathrm{Sr}_{2} M^{\prime} \mathrm{RuO}_{6}$ and $\mathrm{Sr}_{2} M^{\prime} \mathrm{SbO}_{6}$. Another interesting observation is the fact that all of the $\mathrm{Sr}_{2} \mathrm{MnMO}_{6}$ compounds show octahedral rotations about the $c$ axis $\left(a^{0} a^{0} c^{-}\right)$, whereas each of the $\mathrm{Sr}_{2} \mathrm{Fe} M \mathrm{O}_{6}$ compounds undergoes a more complex form of octahedral tilting (either $a^{-} b^{+} a^{-}$or $a^{-} b^{-} a^{-}$). Finally, we note that perovskite oxides containing $\mathrm{Ca}^{2+}$ as the $A$-site cation and a 1:1 distribution of $\mathrm{Cu}^{2+}$ and $M^{6+}$ on the octahedral sites (i.e. $\mathrm{Ca}_{2} \mathrm{CuWO}_{6}$ and $\mathrm{Ca}_{2} \mathrm{CuTeO}_{6}$ ) have not been reported in the literature. The combined implication of these observations is that, while $a^{0} a^{0} c^{-}$appears perfectly compatible with the development of a CJTD in ordered perovskites, further tilting $\left(a^{-} b^{+} a^{-}\right.$in particular) seems to destabilize orbital ordering.

\section{Conclusions}

The crystal chemistry of perovskites containing an active J-T ion is diverse. The magnitude and orientation of the observed CJTD not only is dependent on the cation-anion pair but also exhibits sensitivity to local cation order and octahedral tilting. The coordination environment of $\mathrm{Mn}^{3+}$ appears to be more sensitive than that of $\mathrm{Cu}^{2+}$ to the transition from a ternary $A M X_{3}$ perovskite to an ordered quaternary $A_{2} M M^{\prime} X_{6}$ perovskite. Octahedral-site cation ordering influences local ordering of the J-T distortions. A large difference in both charge and size is responsible for the observation that cation ordering is always present in $\mathrm{Cu}^{2+}-M^{6+}$ perovskites at room temperature. J-T distortions can be enhanced by chemical pressure induced by oversized $A$-site cations $(\tau>1)$, as demonstrated by the behavior of $\mathrm{RbCuF}_{3}$. In ternary $A M X_{3}$ perovskites, increased octahedral tilting enhances the size of the CJTD. Rock-salt ordering of the octahedral-site cations is incompatible with $a c$-plane ordering owing to the creation of two different sites for the octahedrally symmetric ion. Orbital ordering along a single axis is more stable for rock-salt ordered $A_{2} M^{\prime} M X_{6}$ compositions with relatively small octahedral-tilting distortions $(\tau>0.98)$. As the octahedral tilting increases in $A_{2} M^{\prime} M X_{6}$ compositions, the orbital order and CJTD diminish, as observed in $\mathrm{La}_{2} \mathrm{CuTiO}_{6}, \mathrm{Ca}_{2} \mathrm{MnSbO}_{6}$ and $\mathrm{Ca}_{2} \mathrm{MnRuO}_{6}$. Thus it appears that the combination of rocksalt cation order, $a^{-} b^{+} a^{-}$octahedral tilting and orbital ordering are not mutually compatible.

\section{References}

Aleksandrov, K. S. \& Misjul, S. V. (1981). Sov. Phys. Crystallogr. 26, 612-618.

Alonso, J. A., Martinez-Lope, M. J., Casais, M. T. \& Fernandez-Diaz, M. T. (2000). Inorg. Chem. 39, 917-923.

Anderson, M. T., Greenwood, K. B., Taylor, G. A. \& Poeppelmeier, K. R. (1993). Prog. Solid State Chem. 22, 197-233.

Anderson, M. T. \& Poeppelmeier, K. R. (1991). Chem. Mater. 3, 476486. 
Azuma, M., Kaimori, S. \& Takano, M. (1998). Chem. Mater. 10, 3124 3130.

Battle, P. D., Blundell, S. J., Claridge, J. B., Coldea, A. I., Cussen, E. J., Noailles, L. D., Rosseinsky, M. J., Singleton, J. \& Sloan, J. (2002). Chem. Mater. 14, 425-434.

Battle, P. D., Gibb, T. C., Jones, C. W. \& Studer, F. (1989). J. Solid State Chem. 78, 281-293.

Brese, N. E. \& O'Keeffe, M. (1991). Acta Cryst. B47, 192-197.

Brown, I. D. (1978). Chem. Soc. Rev. 7, 359-376.

Brown, I. D. (2003). http://www.ccp14.ac.uk/ccp/web-mirrors/ i_d_brown (accessed August 2003).

Burdett, J. K. (1981). Inorg. Chem. 20, 1959-1962.

Buttner, R. H., Maslen, E. N. \& Spadaccini, N. (1990). Acta Cryst. B46, 131-138.

Chakhmouradian, A. R. \& Mitchell, R. H. (1998). J. Solid State Chem. 138, 272-277.

Cussen, E., Rosseinski, M. J., Battle, P. D., Burley, J. C., Spring, L. E., Vente, J. F., Blundell, S. J., Coldea, A. I. \& Singleton, J. (2001). J. Am. Chem. Soc. 123, 1111-1122.

Cussen, E. J., Vente, J. P., Battle, P. D. \& Gill, T. C. (1997). J. Mater. Chem. 7, 459-463.

Daoud-Aladine, A., Rodriguez-Carvajal, J., Pinsard-Gaudat, L., Fernandez-Diaz, M. T. \& Revcolevschi, A. (2002). Phys. Rev. Lett. 89, 097205.

Gateshki, M. \& Igartua, J. M. (2003). J. Phys. Condens. Matter, 15, 6749-6757.

Gateshki, M., Igartua, J. M. \& Hernandez-Bocanegra, E. (2003). J. Phys. Condens. Matter, 15, 6199-6217.

Giaquinta, D. M., Davis, W. M. \& zur Loye, H.-C. (1994). Acta Cryst. C50, 5-7.

Glazer, A. M. (1972). Acta Cryst. B28, 3384-3392.

Glazer, A. M. (1975). Acta Cryst. A31, 756-762.

Goldberger, J. E., Santhosh, P. N., Woodward, P. M., Karen, P. \& Moodenbaugh, A. R. (2004). Chem. Mater. Submitted.

Goldschmidt, V. M. (1926). Naturwissenschaften, 14, 477-485.

Goodenough, J. B. (1998). Annu. Rev. Mater. Sci. 28, 1-27.

Hidaka, M., Eguchi, T. \& Yamada, I. (1998). J. Phys. Soc. Jpn, 67, 2488-2494.

Howard, C. J., Kennedy, B. J. \& Woodward, P. M. (2003). B59, 463471.

Howard, C. J. \& Stokes, H. T. (1998). Acta Cryst. B54, 782-789.

Hutchings, M., Samuelsen, E. J., Shirane, G. \& Hirakawa, K. (1969). Phys. Rev. 188, 919-923.
Iwanaga, D., Inaguma, Y. \& Itoh, M. (1999). J. Solid State Chem. 147, 291-295.

Jiang, B., Zuo, J. M., Chen, Q. \& Spence, J. C. H. (2002). Acta Cryst. A58, 4-11.

Kaiser,V., Otto, M., Binder, F. \& Babel, D. (1990). Z. Anorg. Allg. Chem. 585, 93-104.

Kanamori, J. (1960). J. Appl. Phys. 31, 14S-23S.

Lee, S.-O., Cho, T. Y. \& Byeon, S.-H. (1997). Bull. Korean Chem. Soc. 18, 91-97.

Lufaso, M. W. \& Woodward, P. M. (2001). Acta Cryst. B57, 725-738.

Lufaso, M. W., Woodward, P. M. \& Goldberger, J. E. (2004). J. Solid State Chem. Accepted.

Marezio, M., Remeika, J. P. \& Dernier, P. D. (1970). Acta Cryst. B26, 2008-2022.

Murakami, Y., Hill, J. P., Gibbs, D., Blume, M., Koyama, I., Tanaka, M., Kawata, H., Arima, T. \& Tokura, Y. (1998). Phys. Rev. Lett. 81 , 582-585.

Murakami, Y., Kawada, H., Kawata, H., Tanaka, M., Arima, T., Moritomo, Y. \& Tokura, Y. (1998). Phys. Rev. Lett. 80, 19321935.

Palacin, M. R., Bassas, J., Rodriguez-Carvajal, J. \& Gomez-Romero, P. (1993). J. Mater. Chem. 3, 1171-1177.

Paolasini, L., Caciuffo, R., Sollier, A., Ghigna, P. \& Altarelli, M. (2002). Phys. Rev. Lett. 88, 106403.

Pauling, L. (1929). J. Am. Chem. Soc. 51, 1010-1026.

Radaelli, P. G., Cox, D. E., Marezio, M. \& Cheong, S.-W. (1997). 55, 3015.

Rodriguez-Carvajal, J., Hennion, M., Moussa, F., Moudden, A. H., Pinsard, L. \& Revcolevschi, A. (1998). Phys. Rev. B, 57, 52595264.

Shannon, R. D. (1976). Acta Cryst. A32, 751-767.

Tezuka, K., Henmi, K. \& Hinatsu, Y. (2000). J. Solid State Chem. 154, 591-597.

Woodward, P. M. (1997a). Acta Cryst. B53, 32-43.

Woodward, P. M. (1997b). Acta Cryst. B53, 44-66.

Woodward, P. M. (1997c). PhD dissertation, Oregon State University, Corvallis, OR, USA.

Woodward, P. M., Cox, D. E., Vogt, T., Rao, C. N. R \& Cheetham, A. K. (1999). Chem. Mater. 11, 3538-3528.

Zimmermann, M., Nelson, C. S., Hill, J. P., Gibbs, D., Blume, M., Casa, D., Keimer, B., Murakami, Y., Kao, C.-C., Venkataraman, C., Gog, T., Tomioka, Y. \& Tokura, Y. (2001). J. Mag. Mag. Mater. 233, 3137. 